Studia Anglica Posnaniensia 51/1, 2016

doi: 10.1515/stap-2016-0001

\title{
LINGUISTICS
}

\section{THE MORPHOLOGICAL TRIGGER OF V-TO-T: THE CASE OF OLD ENGLISH*}

\author{
CONCHA CASTILLO ${ }^{\dagger}$
}

University of Màlaga

\begin{abstract}
This paper deals with the phenomenon of V-to-T movement, which is one of the major parameters differentiating Romance from the majority of modern Germanic languages, and it defends the idea that rich morphology is the cause or trigger of V-to-T: in Romance, in a modern Germanic language like Icelandic, and very particularly in Old English, the precursor of the modern English language. More generally, the discussion endorses the idea that all Germanic languages used to be V-to-T languages in their old periods. I begin by arguing that verbal forms in Spanish contain a specific kind of segment, namely the stem or thematic vowel, which gives rise to morphological variations or asymmetries across tenses in the language. Such a productive system of stem verb classes is also shown to be the case in Icelandic, though not in German (which is therefore rendered as non-V-to$\mathrm{T}$ ), and ultimately it is acknowledged for a language like OE. The hypothesis is that the syntactic computation of $(\mathrm{OE})$ verbal forms demands it that the speaker first identifies the verb class that the form in question belongs to before tackling the processing of tense morphology and agreement morphology. In pure syntactic terms, the stem or thematic vowel segment is identified in the present account with a $v$-feature that $\mathrm{T}$ must value, which valuation is realised by means of the displacement of the verb to the T head, that is, by means of V-to-T movement. After the valuation of T's $v$-feature comes the valuation of $\tau$-features and $\varphi$-features, respectively.
\end{abstract}

Key words: V-to-T movement, Romance, Icelandic, German, Old English, old Germanic languages, stem or thematic vowel, T's $v$-feature, $\tau$-features, $\varphi$-features.

* I would like to thank the anonymous reviewers to Studia Anglica Posnaniensia for their comments and suggestions, and also for the revision of the style. All remaining errors are my responsibility.

$\dagger \quad$ Corresponding author: Concha Castillo, ccastillo@uma.es, Department of English, Faculty of Arts, Campus de Teatinos 29071, Málaga, Spain. 


\section{Introduction}

The phenomenon of V-to-T movement, which is considered to oppose Romance languages on the one hand and a large majority of Germanic languages on the other hand, has been the target of analysis of the so-called Rich Agreement Hypothesis or $R A H$, which contends that the movement of the finite verb to the $\mathrm{T}$ (ense) head is caused by rich agreement morphology, that is, rich person and/or number morphology, combined or not with rich tense morphology: see e.g. Roberts (1985, 1993), Platzack \& Holmberg (1989), Rohrbacher (1994, 1999), or Vikner (1997), where it is stated specifically that "V-to-T movement applies if and only if person morphology is found in all tenses" (p. 201). The simplified labelled-bracketing configuration in (1a) shows in an informal way a sequence where no V-to-T applies, just the movement of $\mathrm{V}$ to the $v$ head, and (1b) corresponds to a sequence where the movement of $\mathrm{V}$ to $v$ is followed by $\mathrm{V}$ to-T movement. ${ }^{1}$

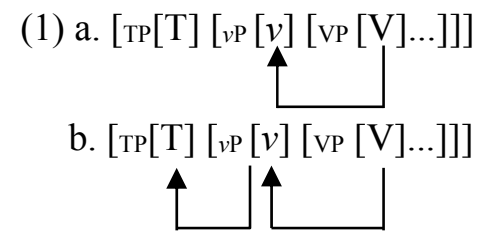

The RAH has not thus far nevertheless appeared to make precise the proper formulation of richness relative to V-to-T, and it has come to be criticised both on the grounds that there are languages with rich verbal morphology that appear to be V-in situ languages and on the grounds that there are languages with scarce verbal morphology that exhibit $\mathrm{V}$-to-T movement. It must also be noted that accounting for the trigger of $\mathrm{V}$-to-T movement is further complicated by the lack of consensus on the use of diagnostic tests in order to acknowledge a given language as V-to-T or V-in situ, as can be easily inferred among others from the works of Thráinsson (2010) or Koeneman \& Zeijlstra (2014): such diagnostic tests are typically the ones postulated mainly since Pollock (1989), namely, the placement of negation or also of medial adverbs like always or often. Thus, the order $\mathrm{V}-\mathrm{Neg}$ or $\mathrm{V}-\mathrm{Adv}$ would arguably indicate that V-to-T movement has applied, whereas Neg-V or Adv-V would indicate just the opposite. However, the syntactic status of negation as e.g. a phrase or a clitic, or the variable position of medial adverbs, can arguably mask the position of $\mathrm{V}$ itself.

\footnotetext{
I assume the standard post-pollockian configuration of a $\mathrm{T}(\mathrm{ense}) \mathrm{P}(\mathrm{hrase})$ merging on top of $v \mathrm{P}$. Further, although the term V-to-T movement is typically used in the literature, it is properly V-to- $v$-to-T movement.
} 
Also, the V2 phenomenon, that is, the movement of $\mathrm{V}$ up into the $\mathrm{C}$ (omplementiser) position above TP can prove to be an obstacle for the actual verification of the movement of $\mathrm{V}$-to-T.

In this paper I argue that the trigger of $\mathrm{V}$-to- $\mathrm{T}$ lies in rich tense morphology in the sense of variations or asymmetries across tenses, which happen to be provoked by the so-called stem or thematic vowel. The proposal consists in that the stem or thematic vowel segment gives rise to variations or asymmetries across tenses in certain languages, which makes the processing or derivation of verbal forms more complex or longer: such languages are V-to-T languages. In minimalist terms, the stem or thematic vowel morpheme or segment is made to correspond in the present approach with a $v$ feature that $\mathrm{T}$ must value in the course of the derivation at narrow syntax.

I defend the hypothesis that Germanic languages are all in their old periods V-to-T languages, in a parallel fashion to Romance languages, though later on, in contrast to Romance, they become non-V-to-T. The exceptions to the latter are: Icelandic, Yiddish and also the Faroese language in its original version, since these three Germanic languages have arguably gone on being $\mathrm{V}$-to-T. ${ }^{2}$ Because of the relevant role that must be conceded, in my view, to the historical perspective, my main focus in this paper is on Old English (OE), and I first use Romance as a testing ground for the account of V-to-T that I would like to propose. The focus of the discussion is specifically on explaining V-to-T in OE in a parallel fashion to V-to-T in a Romance language like Spanish. In order to support the present account of V-to-T I also use Icelandic on the one hand and German on the other, since these languages are very similar to each other as regards rich agreement morphology, and also rich tense morphology (in the sense of number of markers as compared to number of persons), though they have each received a different treatment in the literature. On the view of rich morphology that is proposed here, Icelandic will be acknowledged as V-to-T and German as a non-V-to- $\mathrm{T}$ language.

As suggested above, a considerable amount of controversy surrounds the literature on $\mathrm{V}$-to- $\mathrm{T}$ given the seeming lack of a complete correlation between rich verbal morphology and the verb movement phenomenon. The controversy in question is mainly between the supporters of a weak version of the RAH on the one hand, who contend that if a language has rich agreement then it has V-to-T, and the supporters of a strong version of the RAH on the other hand, who contend that only rich agreement can be the cause of V-to-T. Bobaljik \& Thráins-

Together with Icelandic, Yiddish and the vernacular variety of Faroese are two other modern Germanic languages generally considered to be V-to-T. The present paper deals only with Icelandic. See nevertheless reference to Faroese in note 15 below, and a brief reference to Yiddish verbal morphology in note 21 . 
son (1998) or also Bobaljik (2002) are in the former group, whereas Koeneman \& Zeijlstra (2014) are to be found in the latter. At the centre of the controversy is not only what is understood by rich morphology but also, as noted above, the position that is adopted as regards the diagnostic tests employed to detect or verify $\mathrm{V}$-to-T.

The present discussion supports a weak version of the RAH, given the existence of such languages like the Swedish dialect of Kronoby, or the Norwegian dialect of Tromsø, which are arguably V-to-T but have poor morphology: see references cited in e.g. Bobaljik (2002:158). Though these languages, all of which belong to the modern Germanic family, fall out of the scope of the present discussion, I would like to suggest that they have developed or are developing into V-to-T languages precisely because they could be ceasing to be V2 languages (Kristin Eide, personal communication): this way, such languages would be replacing one instance of verb movement (V2) for another (V-to-T), in spite of the fact that their original syntax is that of V2 and non-V-to-T. Thráinsson (2010) provides an explanation of sentential order in these languages with poor morphology but with V-to-T as based on the syntax of adverbs (in combination with the structural conditions proposed by the author to account for V-to-T, which are incidentally those in Bobaljik \& Thráinsson (1998)). ${ }^{3}$ As for languages with rich agreement morphology but no V-to-T, see reference to Faroese in Section 3.

The paper is organised as follows. In Section 2 I give details about the position adopted in the present paper on $\mathrm{OE}$ as a V-to-T language. Section 3 is a brief statement on the positions in the literature as regards Icelandic and German as V-to-T and V-in situ, respectively. Subsequently, Section 4 is where I identify the type of morphological richness that I would like to propose as the cause of V-to-T for Romance vs. (modern) Germanic, and ultimately for OE. Specifically, I deal first with Spanish, then with German and with Icelandic, and in Section 4 I deal with the morphological trigger of V-to-T in OE. In Section 5 I establish a correlation between the morphological segment responsible for $\mathrm{V}$ to-T and a specific syntactic feature that T must value against $v$, and this I do within a minimalist Agree framework as conveniently specified. In Section 5.2 I describe other morphological approaches to V-to-T.

Specifically, Thráinsson argues that the order V-Adv can be due to the fact that the adverb projects a functional projection of its own in between $\mathrm{T}$ and $v$, and therefore, despite the scarce agreement morphology, the verb must necessarily move to $\mathrm{T}$ in order to reach for the relevant morphology. The reader is referred to a summary of Bobaljik \& Thráinsson's (1998) proposal in Section 5.2 of the paper. 
2. On the V-to-T phenomenon in Romance vs. Germanic: The specific case of OE

It is widely known that two major groups of languages stemming from IndoEuropean, (modern) Romance languages on the one hand and (modern) Germanic languages on the other, came to be characterised within generative theory (specifically, in the GB era) as V-to-T movement languages vs. non-V-to-T languages, respectively. The issue of the $\mathrm{V}$-to- $\mathrm{T}$ phenomenon (or rather, initially, V-to-I phenomenon) can be said to have its origins in works like Emonds (1978), Kosmeijer (1986), Holmberg \& Platzack (1988), Platzack (1988), and very importantly Pollock (1989), which establish specific diagnostic tests that serve as evidence that V-to-T has applied: namely, the position of negation and of certain adverbs like frequency adverbs before the finite verb in surface structure. NegP is argued to be placed above VP (or more properly $v \mathrm{P}$, in later minimalist theory), and similarly frequency adverbs such as often or always are argued to occupy a position in the verbal phrase periphery, which means that for the finite verb to appear in the phonetic string to the right of negation or frequency adverbs is evidence that it itself has not risen to the $T$ head but has instead stayed put within its $v \mathrm{P}$ projection. Such is the case for the English or Swedish structures in (2) below vs. the Spanish or French structures in (3). The use of dummy do is of course an additional proof in English that no V-to-T (of lexical verbs) applies. ${ }^{4}$ The labelled specifications in (2c) and (3c) show the absence vs. presence of movement of the verb $(v)$ to the T head - note the position of the adverb to the leftmost position of the verbal phrase.

(2) a. John always travels by train / John did not meet Mary English

b. om hom inte köpte boken ${ }^{5} \quad$ Swedish

whether she not bought book-the

'whether she didn't buy the book'

$4 \quad$ As is well known, current syntactic theory argues that auxiliaries are externally Merged in T (or, using an older term, base-generated in T) on a general basis. However, according to traditional generative grammar, auxiliaries are Merged on a node lower than $\mathrm{T}$, whether an Aux node (as in Klima 1964) or a V node (as in Ross 1969). Also, a widely-extended trend, which I assume in this discussion, distinguishes between modals on the one hand, and the have and be auxiliaries and do on the other, in that only the former externally Merge in T, a circumstance that would explain their always being inflected (specifically, tense morphology inflection). On this account, V-to-T movement would affect only the have/be auxiliaries and $d o$, which would have to move from Aux or otherwise $\mathrm{V}$ into $\mathrm{T}$ in the course of the derivation (internal Merge).

5 A subordinate clause is illustrated on this occasion since main clauses are typically V2 in Swedish. Therefore, whether V-to-T movement has actually applied in the latter cannot be clearly acknowledged. 
(3) a. Juan viaja siempre en $\operatorname{tren}^{6}$

Spanish John travels always by train 'John always travels by train'

b. Jean mange pas du chocolat / Jean embrasse souvent Marie John eats not chocolate John kisses often Mary 'John doesn't eat chocolate' / 'John often kisses Mary'

c. $\left[\operatorname{Tr}[\mathrm{T}]\left[{ }^{\circ \mathrm{P}}[\mathrm{AdvP}][v][\mathrm{vp}[\mathrm{V}] \ldots]\right]\right] \quad(=\mathrm{V}$-to- $v$; subsequently, $v$-to-T $)$

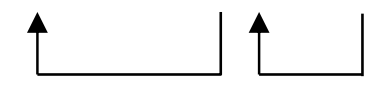

French

Getting closer to the focus of analysis in this paper, the period that antecedes that of Modern English, namely Middle English (ME), is generally agreed in the literature to exhibit V-to-T movement (see Roberts 1993), since negation, or also medial adverbs surface to the right of the finite verb (in a fashion similar to (3a) above). And the same opinion as for (West Germanic) ME is found for languages belonging to the branch of North Germanic at approximately the same time: see e.g. Platzack (1988) for Old Swedish, or Vikner (1995) for Old Danish, or also more recently Faarlund (2004) in connection with Old Norse. In effect, virtually all extant written texts from North Germanic languages in their old periods are contemporary with $\mathrm{ME}$ and are analysed in the cited literature as V-to-T. The structures in (4) illustrate ME as a V-to-T language - note the order V-Neg in (4a), which arguably shows that the verb has moved to Tense, and the order V-Adv in (4b), which similarly suggests that the verb moves over the adverb. In a parallel fashion, the structures in (5) can serve as evidence of Old Norse as V-to- $\mathrm{T}$ - note again the occurrence of negation after the finite verb.

(4) a. Wepyng and teres counforteth not dissolute laghers weeping and tears comfort not dissolute laughers

(Roberts 1993: 250) ${ }^{7}$

6 It must be noted that frequency adverbs can also appear before the finite verb in Spanish, as in (i) below, though such an ordering appears to be the result of multiple base-generation of adverbs in the language.

(i) Juan siempre viaja en tren John always travels by train

7 In this and all other examples, only the secondary source from which the original text has been taken is cited. The reader can follow the reference to the primary sources. 
b. Here men vndurstonden ofte by pis nyzt pe ny3t of synne here men understood often by this night the night of $\sin$

(5) a. ef herra Sigvatr er eigi í dalinum

(Han 2000: 279) if lord Sigvat is not in vallley-the 'if Lord Sigvat is not in the valley'

(Faarlund 2004: 225)

b. ef konungr bannaði eigi

if king $\mathrm{N}$ forbade not

'if the King did not forbid it'

(Faarlund 2004: 251)

However, a controversy exists in the literature as to whether the immediate predecessor of ME, that is, Old English (OE), is a V-to-T language or not. After an analysis of the extant texts in Old High German (OHG), the ancestor of modern German that is more or less contemporary with OE, Axel (2007) concludes that verb movement in this language is to $\mathrm{C}$, and that there is no full-proof evidence of V-to-T movement independent of the cited V2 movement. ${ }^{8}$

The controversy about V-to-T in OE is due in a big part to the fact that the above-mentioned diagnostic tests of the position of negation or of medial adverbs do not yield the same clear-cut results as they do in ME, or otherwise in Romance languages, whether old or modern. As regards negation, the element $n e$ 'not' commonly behaves, as is well known, as a prefix in OE, which means that it occurs immediately to the left of the finite verb (6a), and cannot be used as evidence of verb movement. Also, ne can optionally cliticise to some verbs (6b). As regards adverbs, the so-called class of medial adverbs does not appear to be restricted to a fixed position, with the result that it is not clear whether the position of e.g. cefre 'ever' in a structure like (6c) is due to the adverb occupying a position to the left of the element it modifies (namely, the non-finite verb) or to it being a VP-adverb that proves that the auxiliary (or would-be auxiliary) has moved.

\footnotetext{
As is well known, together with North Germanic and West Germanic, East Germanic is another branch of Old Germanic, and Gothic its exponent language. This paper, however, does not deal with Gothic, which has incidentally been described as being represented by too small a number of texts. See Axel (2007) for references to the Gothic. On the other hand, as a reviewer points out, Eythórsson (1995) notes that Gothic appears to be V-in situ (at least as regards neutral declarative clauses).
} 
(6) a. ...hie ne dorston pær on cuman they not dared there in come '...they did not there enter there'

b. He nolde beon cyning / Nat ic, cwæð Orosius, hwæðer... he neg-want to-be king not-know I said Orosius which 'He didn't want to be king' / 'I don't know, said Orosius, which...'

(Traugott 1992: 268; 266)

c. Hwa wolde me æfre gelyfan...?

who would me ever believe

'Who would ever believe me...?'

(Fischer et al. 2000: 142)

Very importantly, the V2 phenomenon can also be an obstacle in OE when trying to verify V-to-T: that is, though there are manifold structures in OE where the finite verb can be safely said to have moved, it is not clear whether it has moved to $\mathrm{T}$ or to $\mathrm{C}$. Whereas the $\mathrm{V} 2$ phenomenon is a crucial factor to take into account in the analysis of OE main clauses, the head-final/head-initial phenomenon determines in a massive way the syntax of subordinate clauses, which means that verb movement is to be verified for $\mathrm{OV}$ and for $\mathrm{VO}$ sequences, and similarly for OVAux sequences and AuxVO sequences.

Now, as noted from Section 1 of the paper, I assume in the discussion that $\mathrm{OE}$ is a $\mathrm{V}$-to-T language, and my purpose is actually to explain the trigger of $\mathrm{V}$ to-T. I will thus restrict myself in Sections 2.1 and 2.2 immediately below to showing in a schematic way various configurations that have been provided in the literature of the last two decades or so that incorporate V-to-T movement either explicitly or implicitly.

\subsection{V-to-T in OE main clauses}

As regards main clauses, I endorse the view that so-called non-operator fronting sequences ${ }^{9}$ with the verb in third position - hence the term verb-third sequences -

9 As assumed extensively in the literature, structures with a so-called operator in initial position - specifically, a wh-phrase, a negative phrase, or an adverb like $p a$ or ponne 'then' are ones characterised by the movement of $\mathrm{V}$ to the $\mathrm{C}$ position, and are thus typical V2 structures (or also operator fronting structures). See (i) below.

(i) a. $\quad$ Why make ye youreself for to be lyk a fool?

why make you yourself for to be like a fool

'Why do you allow yourself to behave like a fool?'

a.' [Spec,CP why [c make [тр уе... [vр ...]]]] 
can be used as evidence of V-to-T independent of V-to-C (that is, of V2). A V2 sequence is illustrated in (7a) below, and the verb-third order in (7b). As is well known, structures like (7a) start declining during the ME period, and are almost lost at the end of ME and beginning of the Modern period, whereas structures like (7b), with a full DP or with a pronoun in subject position, get more and more frequent in the course of the OE period (see e.g. Haeberli 2002a, b) and are of course ordinary structures in the contemporary language (I ignore the OV order of this specific example). The loss of (7a) can be said to result from English ceasing to be a V2 language (in contrast to the rest of Germanic).

(7) a. On pis gær wolde pe king Stephne tæcan Rodbert in this year wanted the king Stephen seize Robert 'During this year king Stephen wanted to seize Robert'

(Fischer et al. 2000: 130)

b. Đas ping we habbad be him gewritene these things we have about him written 'These things we have written about him'

(Fischer et al. 2000: 130)

Well-known works like Pintzuk (1991, 1993, 1999), Kroch \& Taylor (1997), Fischer et al. (2000), or Haeberli (2002a, b, 2005) all defend the view that the (finite) verb raises to a position below $\mathrm{C}$, though some identify such a position as I(nflection) proper, or as Agr(eement), or just as some kind of F(unctional) projection. What matters for the purpose of the present discussion is that it is plausible to assume that V-to-T movement indeed applies in the grammar of OE. In (8) below are shown the labelled-bracketing configurations that would correspond roughly speaking to each of the cited analyses.

(8) a. [Ipon pis $\operatorname{gær}_{i}$ [Iwolde ${ }_{v}\left[t_{v}\right.$ [vppe king Stephne tæcan Rodbert $\left.\left.\left.t_{i}\right]\right]\right]$

b. [IPðas ping [Iwe $_{h}-h a b b a \partial_{v}\left[t_{v}\left[v p b e\right.\right.$ him gewritene $\left.\left.\left.\left.t_{h} t_{i}\right]\right]\right]\right]$

(Pintzuk 1991, 1993, 1999)

(9) a. [стоn pis gær $\left[\right.$ [с] [Fе[Fwolde $\left.{ }_{v}\right]$ [тppe king Stephne [ t [vptæcan Rodbert

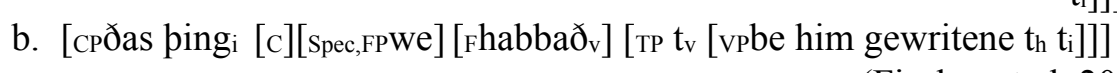

b. ponne is an port on suðeweardum pæm lande...

then is one port in south-of that land

'Then there is a port in the south of that country...'

(Traugott 1992: 224) 


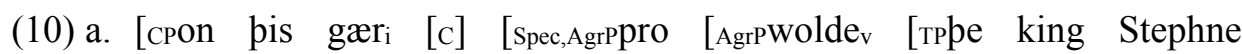
[ $\mathrm{t}_{\mathrm{v}}$ [vptæcan Rodbert $\left.\left.\left.\left.\left.\left.\mathrm{t}_{\mathrm{i}}\right]\right]\right]\right]\right]\right]$

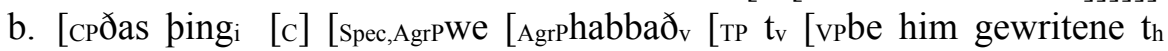

$\left.\left.\left.\left.\left.\mathrm{t}_{\mathrm{i}}\right]\right]\right]\right]\right]$

(Haeberli 2002a, b)

In contrast to the above configurations, works like van Kemenade (1987), Biberauer \& Roberts (2005/2008), or Biberauer \& van Kemenade (2011) defend the idea that the verb in the structures above moves to $\mathrm{C} .{ }^{10} \mathrm{I}$ would like to recall from Section 1 above that I assume the more general idea that V-to-T applies in the older stages of Germanic languages, and then disappears in their modern periods (arguably with the exceptions of Icelandic, Yiddish, or the original Faroese language). All in all then, it is actually one of two scenarios that can be endorsed in a study of verb movement in the Germanic family. If, on the one hand, it is considered that Germanic languages in their old periods are V2 but non-V-to-T languages, then it is necessary to explain why e.g. the English language becomes $\mathrm{V}$-to- $\mathrm{T}$ in the ME period (see Section 2 above), and then loses V-to-T in the course of the Modern period. Biberauer \& Roberts (2005/2008) offer an explanation of $\mathrm{V}$-to- $\mathrm{T}$ in ME that is actually unrelated to morphology: the authors argue that V2 structures with the subject in initial position come to be reanalysed as V-to-T structures (see (11) below). Subsequently, they explain the loss of V-to-T as based on scarce morphology, more specifically on the scarce number of synthetic tenses. The reader is referred to Section 5.2 of the paper for a review of their approach.

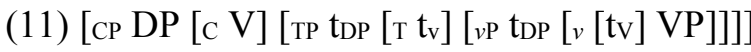 $\rightarrow[$ те DP [т V] [vр tDP [v tv] VP]]}

If, on the other hand, it is considered that Germanic languages are V-to-T languages in their old periods (as assumed in the present discussion), and that they are also V2 languages with the exception of English, which is not fully V2 (as is still the case nowadays in the Germanic family), then what is necessary is to explain the trigger of V-to-T, and this is what I propose to do in Sections 4 and 5 of the paper.

10 Specifically, the configuration defended by van Kemenade (1987) would be as in (i) below and, for their part, Biberauer \& Roberts (2008) postulate the mechanisms of VP-pied piping and $v \mathrm{P}$-pied piping as ones explaining the movement to Spec,TP originally in OE: see (ii).

(i) a. [CPon pis gær $_{i} \quad$ [cwolde ${ }_{v}$ [IPpe king Stephne $\left[t_{v}\right.$ [vptæcan Rodbert $\left.\left.\left.\left.t_{i}\right]\right]\right]\right]$ b. [срðas ping [cwe $_{h}-$ habba $_{\mathrm{v}}$ [IP [ $\mathrm{t}_{\mathrm{v}}$ [vpbe him gewritene $\left.\left.\left.\left.\left.\mathrm{t}_{\mathrm{h}} \mathrm{t}_{\mathrm{i}}\right]\right]\right]\right]\right]$

(ii) a. [cron pis gæri [cwolde ${ }_{v}$ [Spec,Tppe king Stephne tæcan Rodbert $\left.\mathrm{t}_{\mathrm{i}}\right]_{\mathrm{h}} \mathrm{T}_{\mathrm{v}} v \mathrm{P}_{\mathrm{h}}$ ]]

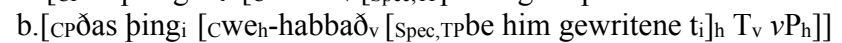




\subsection{V-to- $\mathrm{T}$ in OE subordinate clauses}

As regards subordinate clauses, it was observed in Section 2 above that OE is a mixed head-final/head-initial language. Now, it must be specified whether this is the case at the base, or whether any one structural type derives from the other. Various positions can be found in this respect in the literature, two of the most widely spread being (i) adopting the so-called LCA or Linear Correspondence Axiom, which entails that $\mathrm{OE}$ (and actually all languages on a general basis) is a head-initial language and that all surface possibilities derive from $\mathrm{VO} / \mathrm{AuxVO}$ (see e.g. Biberauer \& Roberts (2005/2008, 2008), Biberauer, Holmberg \& Roberts (2008)); (ii) considering OE as a mixed head-final/head-initial language at the base, which entails that OV/OVAux sequences derive from a head-final configuration, and $\mathrm{VO} / \mathrm{AuxVO}$ sequences derive from a head-initial configuration (see Pintzuk (1999, 2002, 2005), Kroch \& Taylor (2000), Taylor \& Pintzuk (2012)). ${ }^{11}$ I will limit myself to acknowledging the viability of V-to-T movement in the sample of sequences listed in (12) below. The set of sequences featuring an auxiliary is completed with orders like SVAuxO, SAuxOV, and SOAuxV. ${ }^{12}$ It must be emphasised that the number and type of movements indicated do not cover all possible analyses of the relevant sequences, though they are arguably the most frequently resorted to in the literature.

(12) a. gif hie him pæs rices upon SOV if they him the kingdom granted 'if they would grant him the kingdom'

(van Kemenade 1987: 16)

a.' V-to-T on a head-final account: movement of S to Spec, T + vacuous movement of $\mathrm{V}$ to $\mathrm{T}^{13}$

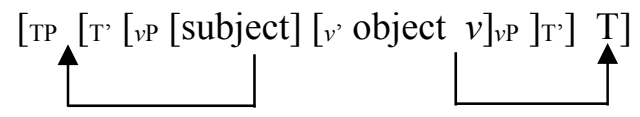

11 Van Kemenade (1987) is one of the first works to study OE syntax with the framework of Government \& Binding theory, and it specifically defends a uniform head-final or OV analysis of the language. On the other hand, Haider (2012) proposes that OE is, like the rest of Germanic languages in their old periods, indeterminate as regards a VO or an OV order.

12 It is widely known that the order VOAux is not possible or virtually unattested in OE, and similarly cross-linguistically, a constraint that is referred to in the literature as FOFC ( Final-over-Final Constraint).

13 As is well known, vacuous movement is any kind of displacement that does not affect the linear order of the string it applies to. 
a." V-to-T on a head-initial account: movement of $\mathrm{V}$ to $\mathrm{T}+$ movement of $\mathrm{O}$ to Spec, $v+$ movement of $\mathrm{S}$ to Spec, $\mathrm{T}$

[тР [т, $[$ т [

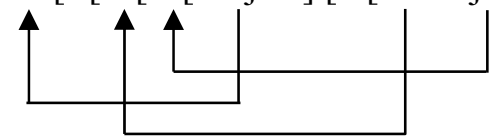

OR movement of $\mathrm{V}$ to $\mathrm{T}+$ remnant movement of $v \mathrm{P}$ (that is, of $\mathrm{SO}$ ) to Spec, $\mathrm{T}$

[тр $\left[\right.$ T’$^{\prime}\left[\right.$ т $\left[v \mathrm{PP}[\right.$ subject $]\left[v^{\prime}\left[v^{\prime} v\right.\right.$ object $\left.\left.\left.]\right]\right]\right]$

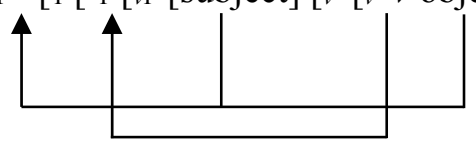

b. pæt hit sie feaxede steorra

that it is long-haired star

'that it is a long-haired star'

(van Kemenade 1987: 39)

b.' V-to-T on a head-final account: movement of $\mathrm{S}$ to $\mathrm{Spec}, \mathrm{T}+$ movement of $\mathrm{V}$ to $\mathrm{T}+$ extraposition of $\mathrm{O}$

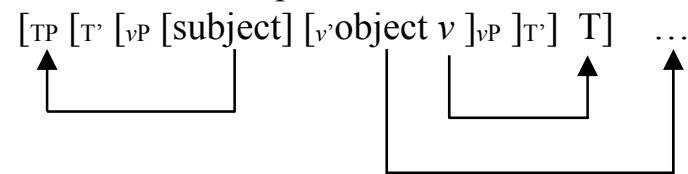

b." V-to-T on a head-initial account: movement of $\mathrm{S}$ to Spec, $\mathrm{T}+$ movement of $\mathrm{V}$ to $\mathrm{T}$

[тр [т, $\left[\right.$ т $\left[\right.$ เр $[$ subject $]\left[v^{\prime}\left[v^{\prime} v\right.\right.$ object $\left.\left.\left.]\right]\right]\right]$

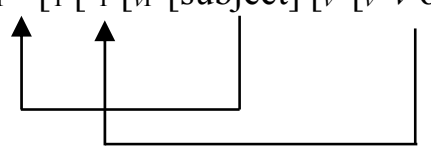

c. gif heo bæt bysmor forberan wolde

SOVAux $^{14}$

if she that disgrace tolerate would

'if she would tolerate that disgrace'

(Taylor \& Pintzuk 2012: 29)

14 I treat auxiliaries as merging externally in their own projections rather than in $\mathrm{T}$. 
c.' V-to-T on a head-final account: movement of $\mathrm{S}$ to Spec, $\mathrm{T}+$ vacuous movement of Aux to T

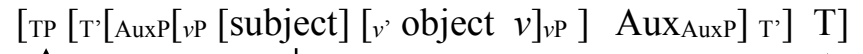
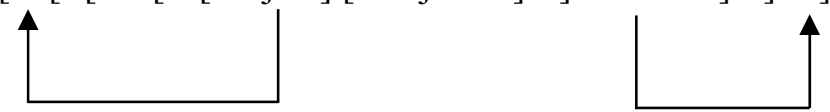

c." V-to-T on a head-initial account: movement of Aux to $\mathrm{T}+$ movement of $\mathrm{O}$ to Spec, $v+$ movement of $v \mathrm{P}$ to Spec, $\mathrm{T}$

[тт [т[[т [AuxPAux] [vP [subject] $\left[v^{\prime}\left[v^{\prime} v\right.\right.$ object $\left.\left.\left.\left.\left.\left.]\right]\right]\right]\right]\right]\right]$

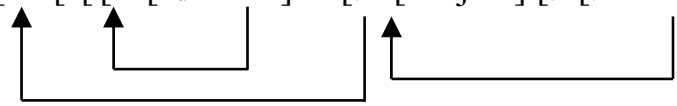

d. swa pæt heo bid forloren bam ecan life

SAuxVO so that it is lost the eternal life

(Taylor \& Pintzuk 2012: 30)

d.' V-to-T on a mixed head-initial/head-final account: movement of S to Spec, $\mathrm{T}+$ movement of Aux to $\mathrm{T}+$ extraposition of $\mathrm{O}$ [тр $\left[T^{\prime}[\right.$ т $[$ AuxpAux [vP [subject $][v,[v$, object $\left.\left.\left.\left.v]]]\right]\right]\right]\right]$
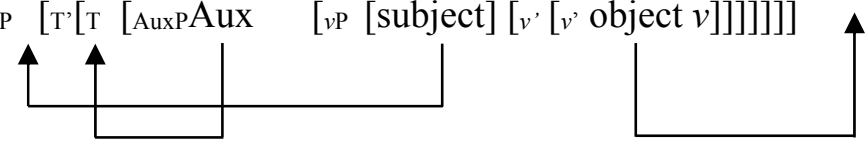

d.' V-to-T on a head-initial account: movement of $\mathrm{S}$ to Spec, $\mathrm{T}+$ movement of Aux to T

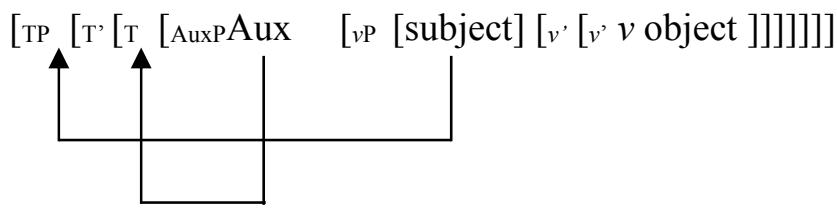

3. V-to-T in modern Germanic languages: the case of Icelandic and the case of German

Together with $\mathrm{OE}$ and a Romance language like Spanish, this paper makes use of Icelandic and German as testing grounds for the proposal of V-to-T (Section 4 below). Icelandic is, together with Yiddish and the vernacular Faroese language, a language with rich agreement morphology (in the classical sense of 
rich person/number features). ${ }^{15}$ As is well known, Icelandic has traditionally been considered by the RAH as a V-to-T language (see e.g. Vikner (1997) or Rohrbacher (1999)). Nevertheless, in the last decade or so some works have contended that the order V-Neg or V-Adv to be found in subordinate clauses other than those known to have main-clause like properties should be considered in an unexceptional way as the result of the V2 phenomenon and not of Vto-T (see e.g. Bentzen et al. (2007a, b), Wiklund et al. (2007), and other references cited in Thráinsson (2010) or in Wood (2015: 39), both of whom actually criticise such a view, and see also Biberauer \& Roberts (2005/2008 27)). Indeed, Thráinsson (2010) and prior to this Bobaljik \& Thráinsson (1998), and also the more recent Koeneman \& Zeijlstra (2014), which come to account for the V-to-T phenomenon from a different perspective than rich agreement morphology in the sense of the bare number of person/number morphemes relative to the number of persons, do use Icelandic as a case study of a V-to-T language. As a result, the general opinion in the literature appears to be on the side of Icelandic as V-to-T. The account proposed here of the V-to-T phenomenon is different from Bobaljik \& Thráinsson (1998) and also, despite the contrasts between the two, from Koeneman \& Zeijlstra (2014), but it shares with these works the analysis of Icelandic as a V-to-T language. In Section $5.2 \mathrm{I}$ deal in general terms with the account provided by Bobaljik \& Thráinsson (1998) and by Koeneman \& Zeijlstra (2014).

Turning to German, this language is particularly interesting for the present discussion because the analysis proposed here renders it as a non-V-to-T language, by contrast with manifold works in the literature, seemingly biased by rich agreement morphology. In effect, as mentioned in Section 1, German shares with Icelandic a similar rich amount of agreement morphology and tense morphology (in the classical sense of number of markers relative to number of persons). On the other hand, the head-final or SOV status of German subordinate structures could demand the use of vacuous movement, which is not very well liked in the general literature. Works defending the classical RAH like e.g. Rohrbacher (1999) opt for assuming that German is V-to-T, and dismiss argu-

15 The vernacular Faroese language is a V-to-T language - as described in Heycock \& Sorace (2006) or in Thráinsson (2010), and several other works by this author - though from this has stemmed one variety, which has by now become the standard, and which appears to be a V-in situ language. Faroese seems to be an excellent testing ground to analyse V-to-T movement, but not specifically the correlation between morphology and V-to-T movement, but the correlation between the autonomous syntax of adverbs and V-to-T movement (see also Thráinsson (2010)). The more recent variety of Faroese therefore does not contradict the fact that rich morphology provokes verb movement, which entails that the processing or computation of the verbal form is arguably the same in either variety of Faroese; rather, the issue at stake is that the order Adv-V is very plausibly to be considered in the case of this more modern variety as attending exclusively to the development of the syntactic behaviour of adverbs. 
ments provided at their time in the literature against the V-to-T status of the language. Specifically, Rohrbacher (1999: 29ff.) explicitly refers to a situation of vacuous movement in case V-to-T is to apply to a head-final configuration. As for Bobaljik \& Thráinsson (1998) or Bobaljik (2002), they acknowledge that their theory predicts that there should be V-to-T in German (see Section 5.2) and conclude that the debate is unresolved.

Nevertheless, Vikner (2005), which is based in turn on Vikner (2001), concludes that German is non-V-to-T after considering, not the rich or poor verbal morphology of the language, but the syntactic behaviour of a particular type of German verb taking one or more prefixes (the reader is referred to the work in question). Also, Haider (2010) supports a non-V-to-T analysis of German, and so do Biberauer \& Roberts (2008), who incidentally provide an account of V-to-T as based on morphology which is reviewed in Section 5.2 of the present paper.

4. The morphological trigger of $\mathrm{V}$-to-T movement: a descriptive account

In Sections 4.1-4.3 I aim to identify the specific morphological segment that could be responsible for the morphological richness that is the trigger of $\mathrm{V}$-to- $\mathrm{T}$, and for this I focus first on Spanish as a Romance language (4.1), then on three modern Germanic languages, namely English, Icelandic, and German (4.2), and ultimately on OE (4.3), which will allow me to acknowledge the precursor of modern English as a V-to-T language. Later, in Section 5, I describe the cited morphological segment as a formal feature: specifically, I use the concepts of valuation and interpretation within a minimalist Probe-Goal Agree framework.

4.1. Morphological richness as provoked by the stem segment: The case of Romance

The idea that I would like to propose is that the morphological richness that is at the base of V-to-T is to be identified with the so-called stem or thematic vowel, in the sense that this segment can provoke systematic variations or asymmetries across the different tenses in the languages in question, in the way to be justified later on. In other words, I would like to argue that the languages that exhibit Vto-T movement are the languages that exhibit productive verb classes as based on stem differences, and that OE is one of those languages. In Section 5 I will contend that the stem vowel segment corresponds with a $v$ feature that $\mathrm{T}$ must value, which will allow me to explain the movement of V-to-T from a theoryinternal point of view. As noted above, I first implement the proposed account on Romance languages. 
Now, the stem of verbs in Romance languages (Spanish, Portuguese, Italian, French,... $){ }^{16}$ that is, languages that are unambiguously analysed as V-to-T, typically consists of a root segment on the one hand and a so-called stem vowel or thematic vowel segment on the other, a situation that these languages inherit from their Latin ancestor: see (13) below. I would like to observe that I assume the opinion in the generative literature on Latin as a V-to-T language - see e.g. Danckaert (2012: 300ff.) - though a work like Ledgeway (2012: 140ff.) argues that $\mathrm{V}$-to-T begins properly in the transition from Latin to Romance, when there emerges a structural position for auxiliaries, namely IP.

(13) root + stem vowel + tense $/$ mood + agreement

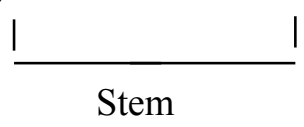

Stem

The above division is exemplified in (14) for the infinitive and for $1 \mathrm{psn} \mathrm{pl}$ of Imperfect Indicative of the three stem-classes available in a Romance language like Spanish, the so-called -ar-class, -er-class, and -ir-class.

(14) a. Infinitive

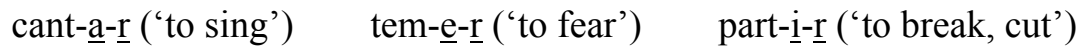
root - [stem vowel] - [infinitive ending]

b. Imperfect Indicative

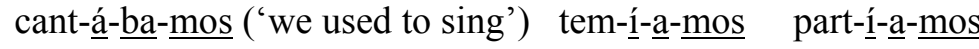
root -[ stem vowel] $-[$ tense/mood] $-[$ person/number]

As discussed by RAE (2009: 182ff.), the proper analysis of verbal forms in the full paradigm must necessarily rely on the acknowledgment of certain segments as null, or otherwise as simply absent or non-existent. This is clearly the case for $1 \mathrm{psn}$ sg of Present Indicative. Below are illustrated various possible segmentations of the cited form for cantar ('to sing'): canto ('I sing'). RAE (2009: $185-186)$ further specifies that the segmentations in (15d) and (15e) are the two preferred options by specialists in the field.

(15) a. cant-o root-[stem vowel+tense/mood+person/number] (i.e. assemblage of all markers)

16 As is widely known, subject agreement is clearly marked on the verb in written French, but not so in the spoken language, where few of the corresponding distinctions are pronounced. Nevertheless, I take such a process of simplification/assimilation in the phonology as independent of the (three-way) division of French verbs as based on the stem segment. 


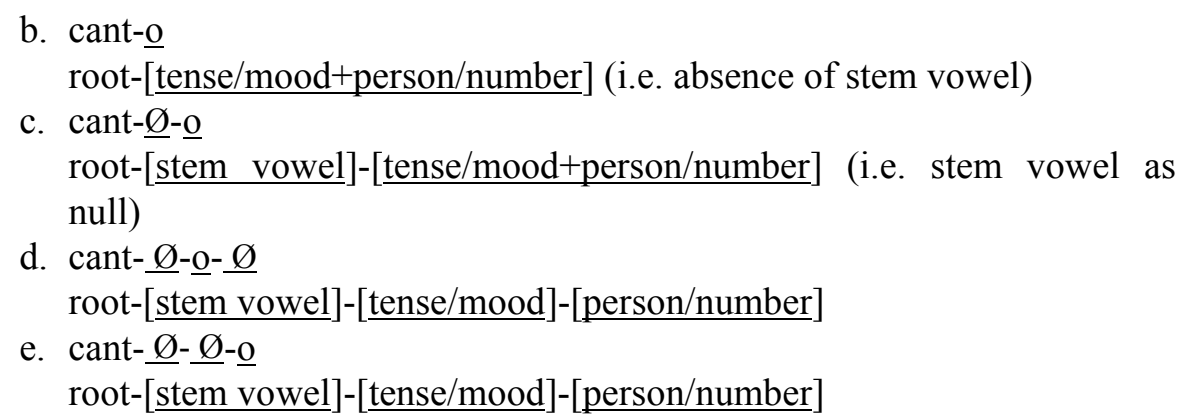

Even the forms corresponding to e.g. Imperfect Indicative, which lend themselves to a neat division into four segments as indicated in (14b), are liable to be analysed in several other ways. RAE (2009: 187) thus emphasises the fact that the segmentation in (14) is the classical one, though those in (16) are also in principle perfectly legitimate.

(16) a. cant- $\underline{\varnothing}-\underline{a b}-\underline{a}-\underline{\operatorname{mos}}$ root -[stem vowel]-[tense][aspect/mood]-[person/number]

b. cant - 므- $\underline{a}-\underline{\operatorname{mos}}$ root -[tense]- [aspect/mood]-[person/number]

In order to show the morphological asymmetries or variations provoked by the stem vowel that, as I would like to argue, ultimately constitute the trigger of Vto-T, I provide a segmentation of all forms in the Spanish paradigm of Indicative in (17) below. Actually, two different segmentations are provided for each form: the first one just differentiates the root from all other markers or segments, and is therefore a neutral one, and the second segmentation, which is one taken from RAE (2009: 196-198), is sensitive to each of the above-cited markers. This second segmentation, that is, the one to the right of the slash, is intended here to show in a clear way the uniformity or symmetry running throughout the overall paradigm. The description of such uniformity or symmetry will be actually the first step in order to discern immediately afterwards the asymmetries or morphological variation also shaping the paradigm, which are the key aspect of the present approach to V-to-T. 
(17)

$$
\begin{aligned}
& \text { cantar 'to sing' } \\
& \text { (-ar class) }
\end{aligned}
$$

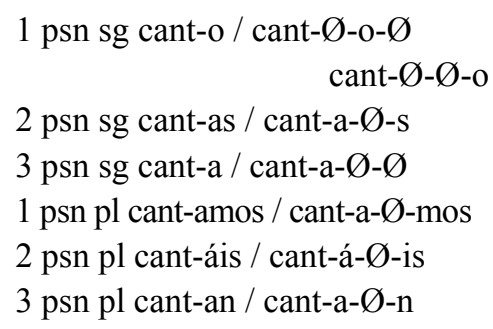

1 psn sg cant-é / cant-Ø-é-Ø

2 psn sg cant-aste / cant-a-ste- $\varnothing$ 3 psn sg cant-ó / cant- $\varnothing$-ó- $\varnothing$ $1 \mathrm{psn}$ pl cant-amos / cant-a-Ø-mos 2 psn pl cant-ásteis / cant-á-ste-is 3 psn pl cant-aron / cant-a-ro-n

1 psn sg cant-aba / cant-a-ba- $\varnothing$ 2 psn sg cant-abas / cant-a-ba-s 3 psn sg cant-aba / cant-a-ba- $\varnothing$ 1 pan pl cant-ábamos / cant-á-ba-mos 2 psn pl cant-ábais / cant-á-ba-is 3 psn pl cant-aban / cant-a-ba-n

1 psn sg cant-aré / cant-a-ré- $\varnothing$ 2 psn sg cant-arás / cant-a-rá-s 3 psn sg cant-ará /cant-a-rá- $\varnothing$ 1 psn sg cant-aremos/cant-a-re-mos 2 psn pl cant-aréis / cant-a-ré-is 3 psn pl cant-arán / canta-rá-n

1 psn sg cant-aría / cant-a-ría-Ø 2 psn sg cant-arías / cant-a-ría-s 3 psn sg cant-aría/ cant-a-ría- $\varnothing$
Spanish - Indicative mood temer 'to fear' (-er class)

partir 'to break, cut' (-ir class)

\section{Present} tem-o /tem- $\varnothing$-o- $\varnothing$
tem- $\varnothing-\varnothing-0$ tem-es / tem-e- $\varnothing$-s tem-e / tem-e- Ø- $\varnothing$ tem-emos / tem-e- $\varnothing$-mos tem-éis / tem-é-Ø-is tem-en / tem-e- Ø-n

\section{Past}

tem-í / tem-Ø-í-Ø

part-í / part-Ø-í-Ø

tem-iste / tem-i-ste- $\varnothing$ tem-ió / tem-Ø-ió-Ø part-iste / part-i-ste- $\varnothing$ part-ió / part-Ø-ió-Ø part-imos / part-i-Ø-mos tem-imos / tem-i-Ø-mos tem-ísteis / tem-í-ste-is tem-ieron /tem-ie-ro-n part-ísteis / part-í-ste-is part-ieron / part-ie-ro-n

\section{Imperfect}

tem-ía / tem-í-a- $\varnothing$ tem-ías / temí-a-s

part-ía / part-í-a- Ø tem-ía / tem-í-a-Ø part-ías / part-í-a-s part-ía / part-í-a-Ø tem-íamos / tem-í-a-mos tem-íais / tem-í-a-is part-íamos/part-í-a-mos part-íais / part-í-a-is tem-ían / tem-í-a-m

\section{Future}

tem-eré / tem-e-ré- $\varnothing$ tem-erás / tem-e-rá-s tem-eré / tem-e-rá- $\varnothing$ tem-eremos/tem-e-re-mos tem-eréis / tem-e-ré-is tem-erán / tem-e-rá-n

part-iré / part-i-ré- $\varnothing$ part-irás /part-i-rá-s part-iré / part-i-rá-Ø part-iremos/part-i-re-mos part-iréis / part-i-ré-is part-irán / part-i-rá-n

\section{Conditional}

tem-ería / tem-e-ría- $\varnothing$

part-iría / part-i-ría- $\varnothing$ tem-erías / tem-e-ría-s part-irías / part-i-ría-s tem-ería / tem-e-ría-Ø part-iría / part-i-ría-Ø 
1 psn sg cant-aríamos/cant-a-ría-mos tem-eríamos/tem-e-ría-mos part-iríamos/part-i-ría-mos 2 psn pl cant-aríais/cant-a-ría-is tem-eríais/tem-e-ría-is part-iríais/part-i-ría-is $3 \mathrm{psn}$ pl cant-arían/canta-a-ría-n tem-erían/tem-e-ría-n part-irían/part-i-ría-n

Let us first acknowledge the marked degree of uniformity that characterises the paradigm above.

(18) a. Agreement markers coincide for each person in all tenses of the three classes

(-ar, -er, and -ir): - $\varnothing_{-},-s^{-},-\varnothing_{-},-$mos$_{-},-i s^{-},-n^{-}$. The only exceptions are:

a.1. 2 psn sg of Past, which is $-\varnothing$ - instead of $-s$ - and,

a.2. depending on the analysis implemented, 1 psn sg of Present (see (15) above).

b. Tense markers coincide for the three classes (-ar, -er, and -ir). The only exceptions are:

b.1. a bilabial plosive tense marker $-b$ - in medial position of the Imperfect of verbs of the -ar class and

b.2. a vocalic marker -ó- for the -ar class vs. a diphthong -ió-for the -er and -ir classes

c. For all three classes (-ar, -er, and -ir), both tense and agreement markers coincide in Future and Conditional, the only differing marker being the stem vowel proper $(-a-,-e-,-i-)$

d. For all persons, the stem vowel coincide in all tenses (i.e. $-a$ - for the $-a r$ class, $-e$ - for the -er class, and $-i$ - for the -ir class). The only exception is:

d.1. the stem vowel for 3 psn sg of Past, which is $-\varnothing$ - for all three classes, and is the origin of the exception in (b.2) above

e. Only for the -er and -ir classes, all markers coincide in Past and Imperfect, including the stem vowel.

f. Only for the -er and -ir classes, all markers coincide in Present, except for 1 and 2 psn pl, where the stem vowel is different

Now, aside from the exceptions contained in (18a-d), which can be considered not to be at all numerous in a set of 90 forms in total, the most uniform situation in a paradigm that is divided into three classes attending to the stem or thematic vowel segment is actually the kind of variation described in (18c) for the Future and the Conditional, since here the corresponding thematic vowel is added to the root, and to this segment is added the tense marker, and to this is finally added the agreement marker.

However, from the two situations depicted in (18e) and (18f) derive two major asymmetries: 
(19) a. The stem vowel differs for Future and Conditional in the -er and -ir classes, but not so for Past and Imperfect

b. The stem vowel for the -er and -ir classes in 1 and $2 \mathrm{psn}$ pl of Present is the same, but not so for remaining persons in the Present

What the paradigm of the Spanish Indicative shows - and the same is replicated for the Subjunctive and the Imperative paradigms, which are not illustrated in the paper for lack of space ${ }^{17}$ - is that, rather than uniformity in the sense that after the root segment is licensed the stem vowel segment, and then the tense segment, and then finally the agreement segment is licensed, there is asymmetry across tenses as imposed by the stem vowel. Basing upon the infinitive then, the speaker must take into consideration the major contrasts in (19) - aside from those in (18a-d). In other words, it is impossible to inflect a verb in Spanish without computing the part that corresponds to the stem or thematic vowel, though not because the stem or thematic vowel figures in all tenses with all their person slots and therefore demands computing as any other marker, but because the stem or thematic vowel determines a certain number of asymmetries (namely, those in (19)) in the overall composition of verbal forms.

It is important to note that the Spanish verbal paradigm contains numerous cases of allomorphic variation or asymmetries that are not provoked by the stem or thematic vowel segment and are therefore irrelevant for the present analysis. Such allomorphic variation typically affects either the vowel or the last consonant in the root: note the diphthongization in sentir 'feel' / siento (I-feel), contar 'count; tell' / cuento (I-count; I-tell), or the fronting of the vowel in pedir 'ask' / pido (I-ask), or velar insertion in tener 'have' / tengo (I-have), or consonant alternation in hacer 'do, make' / hago (I-do, I-make). The reader is referred to RAE (2009: 225ff; 235ff.)

4.2 Morphological richness as provoked by the stem segment: The case of Icelandic vs. English or German

The next step now is to try and acknowledge whether the situation that we have seen in Spanish is also found in modern Germanic languages, irrespective of whether these are agreed to be non-V-to-T, like English or Mainland Scandinavian languages (Norwegian, Swedish, Danish), or whether their verb movement status has been questioned at some time or other. As advanced in Section 1, it is particularly two languages that the present discussion is interested in in this respect: one is German and the other is Icelandic. It will be shown that the analysis proposed in the section immediately above renders Icelandic but not Ger-

17 The reader is referred to RAE (2009:196-198) for these paradigms. 
man as a language akin to Spanish as regards tense variations or tense asymmetries. The conclusion will be that the analysis of V-to-T proposed in this paper supports Icelandic as a V-to-T language and German as non-V-to-T. I focus first on English, and then I pass on to German and Icelandic.

In English, all verbal forms in Present are overtly identical to the root except for 3 psn sg, which is marked by the addition of the suffix $-s$ (and this again except for the case of modals, which of course do not add any suffix $-s$ ). As for Past, all forms (of regular verbs) add a suffix -ed in a uniform way and no further overt suffix. ${ }^{18}$

\begin{tabular}{cc} 
(20) English - Indicative mood \\
\multicolumn{2}{c}{ knock } \\
Present & Past \\
1 psn sg knock & knock-ed \\
2 psn sg knock & knock-ed \\
3 psn sg knock-s & knock-ed \\
1 psn pl knock & knock-ed \\
2 psn pl knock & knock-ed \\
3 psn pl knock & knock-ed
\end{tabular}

Since $-s$ can be analysed as an agreement marker - both historically and from a synchronic point of view - and since historically there used to be an agreement marker for each person in the past following the marker -ed-, then it seems valid to entertain a segmentation for English Past as shown in (21), where -ed-is the tense marker and $-\varnothing$ is the agreement marker. And this in turn will lead us to positing that the agreement markers for Present are $-s$ for $3 \mathrm{pn} s g$, as just mentioned, and $-\varnothing$ for all other persons - see (21) again. As for the tense marker in Present, it is widely known that no Germanic language has any such overt element, either historically or from a synchronic perspective. As was implemented on the Spanish Indicative paradigm above, it seems possible to entertain at least two kinds of analysis, one where the cited marker is $-\varnothing$, and another where it is simply absent: both these segmentations are shown in (21).

18 In a trivial way, the addition of so-called derivational affixes would render stems as different from roots proper, whether in Romance or in Germanic, including English: see e.g. (i). Nevertheless, derivational affixes are completely irrelevant for the present discussion.

(i) activ-ate $+\tau$-feature and/or $\varphi$-feature endings

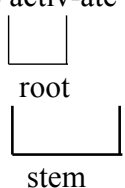


Past

1 psn sg knock- $/ /$ knock- $\varnothing-\varnothing$

knock-ed-Ø

2 psn sg knock- $\varnothing / /$ knock- $\varnothing-\varnothing$

knock-ed- $\varnothing$

3 psn sg knock-s // knock- $\emptyset$-s

knock-ed-Ø

1 psn pl knock- $\varnothing / /$ knock- $\varnothing-\varnothing$ knock-ed- $\varnothing$

2 psn pl knock- $\varnothing / /$ knock- $\varnothing-\varnothing$ knock-ed- $\varnothing$

3 psn pl knock- $\varnothing / /$ knock- $\varnothing-\varnothing$ knock-ed- $\varnothing$

As for the stem or thematic vowel, this marker does not exist in modern English, which entails for the concepts of root and stem to be identified as exactly the same segment for all finite forms of the language: see (22).

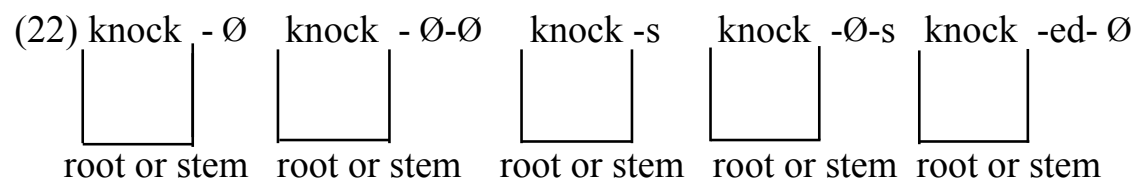

Passing on now to German and Icelandic, I would like to begin by highlighting that both languages feature distinct agreement markers in an abundant way throughout their paradigm. In $(23 a, b)$ below, two of the four synthetic tenses of a regular verb in each language are illustrated. As shown, three overt segments are distinguished for Past Indicative: one for the root, another for the tense marker, and another for the agreement marker. The contrast between the cited agreement marker in these paradigms and that in English (21) above is a major one: whereas English features - $\varnothing$ for all six persons in Past Indicative, German features four distinct overt forms, and Icelandic for its part features six distinct overt forms. ${ }^{19}$ As for Present Indicative, German exhibits again four distinct overt markers, and Icelandic also features four. Further, in order to simplify things, the segment corresponding to tense in the Present of both languages is missing in (23), since the main purpose is to acknowledge the much richer array of overt agreement markers in German or Icelandic as compared to English. As observed above in relation to English, the cited tense segment for Present Indicative can arguably be analysed as $-\varnothing$-, or as simply absent. A more specific segmentation of one form chosen at random like e.g. 2 psn sg from both paradigms in both languages is offered in (24) and (25).

19 Incidentally, Bobaljik \& Thráinsson (1998: 59) observe that Past forms can be analysed in two different ways: either by taking -ði-/-ðu- as the tense marker, or just - $ð-$, which is the specific segmentation chosen here. In case the first choice is taken, then the agreement marker for three persons would be analysed as $-\varnothing$, which would mean for there to be three overt agreement markers for Past Indicative in the language, namely $-r,-m$, and - $\partial$. 


$\begin{array}{lll}\text { (23) a. German - Indicative mood } \\ \text { kaufen 'to buy' } & \\ & \text { Present } & \text { Past } \\ 1 \text { psn sg } & \text { kauf-e } & \text { kauf-t-e } \\ 2 \text { psn sg } & \text { kauf-st } & \text { kauf-t-est } \\ 3 \text { psn sg } & \text { kauf-t } & \text { kauf-t-e } \\ 1 \text { psn pl } & \text { kauf-en } & \text { kauf-t-en } \\ 2 \text { psn pl } & \text { kauf-t } & \text { kauf-t-et } \\ 3 \text { psn pl } & \text { kauf-en } & \text { kauf-t-en }\end{array}$

(24) a. 2 psn sg Present: kauf- $\underline{\varnothing}$-st

b. Icelandic - Indicative mood ætla 'to plan, intend'

Present Past

ætla- $\varnothing \quad$ ætla-ð-i

ætla-r ætla-ð-ir

ætla-r $\quad$ ætla-ð-i

ætl-um ætlu-ð-um

ætl-ið ætlu-ð-uð

ætl-a æatlu-ठ̀-u

root-[ tense]-[person/number] root-[person/number]

b. 2psn sg Past: kauf-t-est

root-[tense]-[person/number]

(25) a. 2psn sg Present:

b. 2psn sg Past:

\author{
ætl-ạ- $\underline{\underline{Q}}-\underline{r}$ \\ // ætl-a-a-r

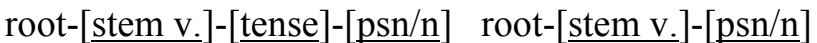 \\ ætl-ạ- $\underline{\partial}-\underline{i r}$ \\ root-[stem v.]-[tense]-[person/number]
}

Despite the high number of agreement segments present in both the German and the Icelandic paradigms, these languages differ from one another in one aspect that is key for the analysis of V-to-T proposed here. In effect, the Icelandic paradigm of regular verbs is organised around stem verb classes, with systematic variations among them, which is not the case at all for German: note the $-a$ - to the right of the hyphen in the paradigm of cetla in (23b) (which is turned into - $u$ - in the Past plural) and also the specification [stem v.] denoting that very segment in (25).

More specifically, the large majority of Icelandic verbs are inflected either like cetla ('to plan, intend') in (23b) above and repeated here below in (26), or like heyra ('to hear'), illustrated in (27). These are the $a$-stem class and $i / j$-stem class, respectively, and each has in addition subclasses of their own, which figure in (26)-(27) to their right. Also, there is a $i$-stem class, represented by the verb segja ('to say') in (28) below, which happens to be a combination of hey$r a$-verbs and telja-verbs in the $i / j$-class. 
Icelandic

\begin{tabular}{|c|c|c|c|c|c|c|}
\hline \multicolumn{4}{|c|}{ ætla 'to plan, intend' } & \multicolumn{3}{|c|}{ tala 'to talk' } \\
\hline $1 \mathrm{psn} \mathrm{sg}$ & & & $\begin{array}{l}\text { Past } \\
\text { ætl-a-ð-i }\end{array}$ & $\begin{array}{l}\text { Present } \\
\text { tal-a- } \varnothing\end{array}$ & & $\begin{array}{l}\text { Past } \\
\text { tal-a- } ð-\mathrm{i}\end{array}$ \\
\hline $2 \mathrm{psn} s \mathrm{sg}$ & & & ætl-a $\underline{a}-ð$-ir & tal-a- $-\mathrm{r}$ & & tal-ä-ð-ir \\
\hline 3 psn sg & & & ætl-a-a-ð-i & tal-â-r & & tal-a-a-ð-i \\
\hline $1 \mathrm{psn} p \mathrm{l}$ & & & ætl-ū-ð-um & töl-um & & töl- $\underline{-u}-ð-u m$ \\
\hline $2 \mathrm{psn}$ pl & ætl & & ætl-ü-ð-uð & tal-ið & & töl-u-u-ð-uð \\
\hline $3 \mathrm{psn} p \mathrm{l}$ & ætl & & ætl-u- - -u & tal-a & & töl-u-ð-u \\
\hline (27) & heyra ("to & near') & lenda ("to & land') & telja ("tc & o count') \\
\hline $1 \mathrm{psn} \mathrm{sg}$ & $\begin{array}{l}\text { Present } \\
\text { heyr-i- } \varnothing\end{array}$ & $\begin{array}{l}\text { Past } \\
\text { heir-Ø-ð-i }\end{array}$ & $\begin{array}{l}\text { Present } \\
\text { lend-i- } \varnothing\end{array}$ & $\begin{array}{l}\text { Past } \\
\text { len-t-i }\end{array}$ & $\begin{array}{l}\text { Present } \\
\text { tel-Ø-Ø }\end{array}$ & $\begin{array}{l}\text { Past } \\
\text { tal-Ø-ð-i }\end{array}$ \\
\hline 2 psn sg & heyr-i- $-\mathrm{r}$ & heir- $\underline{\varnothing}$-ð-ir & lend-i-r & len-t-ir & tel-馬-r & tal-Øַ-ð-ir \\
\hline 3 psn sg & heyr-i- $-\mathrm{r}$ & heir-互-ð-i & lend-i-r & len-t-ir & tel- $\underline{\varnothing}-\mathrm{r}$ & tal-Ø̄-ð-i \\
\hline $1 \mathrm{psn} p \mathrm{l}$ & heyr-um & heyr-足-ð-um & lend-um & len-t-um & tel-j-um & töl-ㅁ-ð-um \\
\hline $2 \mathrm{psn}$ pl & heyr-ið & heyr-Øַ-ð-uð & lend-ið & len-t-uð & tel-Ø-ið & töl-Ø-Ø-ð-uð \\
\hline $3 \mathrm{psn} p \mathrm{pl}$ & heyr-a & heyr-Øַ-ð-u & lend-a & len-t-u & tel-j-a & töl-Øַ-ð-u \\
\hline
\end{tabular}

\begin{tabular}{|c|c|c|}
\hline $1 \mathrm{psn} \mathrm{sg}$ & $\begin{array}{l}\text { Present } \\
\text { seg-i- } \varnothing\end{array}$ & $\begin{array}{l}\text { Past } \\
\text { sag-Øַ-ð-i }\end{array}$ \\
\hline 2 psn sg & seg-i-r & 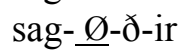 \\
\hline 3 psn sg & seg-i-i-r & sag- $\underline{\varnothing}-ð-i$ \\
\hline $1 \mathrm{psn} p \mathrm{pl}$ & seg-j-um & 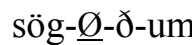 \\
\hline $2 \mathrm{psn} p l$ & seg-Ø-іð & sög-Ø-ð-uð \\
\hline 3 psn pl & seg-i-a & sög-Øַ-ð-u \\
\hline
\end{tabular}

The cetla-class, or $a$-stem class, features an original stem or thematic vowel $-a$ from the ancestors of Icelandic, whereas the heyra-class, or $i / j$-stem class, features front mutation of the cited original thematic vowel $-a$-. As for the $i$-stem class, represented by segja in (28), these verbs feature the corresponding $-i$ vowel in Present (which is turned into $-j$ - before $-a$ - or $-u$-), and their root vowel is not affected by front mutation in Past forms, in a similar fashion to telja-verbs in the $i / j$-stem class.

Now, a property that is shared by all classes is that the thematic vowel is dropped before another vowel. In addition to this, there are allomorphic variations affecting some of the classes, but which are not specifically relevant to the present analysis. Such variations are to be likened to the ones in the Spanish paradigm mentioned at the very end of Section 4.1. Among these are the following: (i) the thematic vowel $-a$ - is turned into $-u$ - in Past plural (so-called labial mutation); (ii) the $-a$ - in the root syllable of the tala-subclass, and similarly 
the $-e$ - in the telja-subclass and also in segja is changed into -o- whenever the ending begins with $-u$ - (back mutation); (iii) the $-d$ - is assimilated to $-t$ - in Past of the lenda-subclass; (iv) as mentioned above, telja- and segja-verbs are not affected by front mutation in Past forms.

Having mentioned the above variations, it must be concluded that the full set of regular verbs in Icelandic is determined by the asymmetries described in (29) below.

(29) A stem vowel figures in Present and Past of the $-a$-class, whereas a stem vowel figures in Present but not in Past of the $-i$-class or the $-i / j$-class, except for the telja-subclass, where a stem or thematic vowel figures just in 1 and $3 \mathrm{psn} \mathrm{pl}$ of Present

The idea that I defend is that in Icelandic, the same as in Spanish, the stem or thematic vowel determines variations or asymmetries in the overall composition of verbal forms, though such asymmetries are more far-reaching in Spanish given the larger number of tenses. This means that the speaker of Icelandic, the same as the Spanish speaker, must compute the segment that corresponds to the stem or thematic vowel before computing the tense segment. I would like to contend that the cited computation or processing of the stem or thematic vowel across tenses is at the base of the V-to-T phenomenon. ${ }^{20}$

Now, in contrast to Icelandic (or to Spanish), knowing the pattern for one verb in German entails knowing the pattern for all verbs generally speaking in the language. There is indeed some amount of allomorphic variation or asymmetry within the set of regular verbs in German, but none of it is imputable to verbs being organised around stem or thematic classes. ${ }^{21}$ Specifically, the variation consists in that: (i) the ending -en is dropped in favour of $-n$ in case the segment it is added to ends in -el or -er (compare (sie) handeln, $3 \mathrm{psn} \mathrm{pl}$ of Present Indicative of the verb handeln 'to act', with (sie) kauften) in (23a) above; or (ii) an epenthetic vowel $-e$ - is added before most endings in order to avoid a large consonant cluster (note the Present Indicative forms arbeitest or arbeitet of the verb arbeiten 'to work', or the Past Indicative forms arbeitete, arbeitetest, arbeitete, arbeiteten,...).

20 A reviewer points out that it could be the case that the two segments are processed in conjunction (especially since in some cases in Icelandic the tense determines whether the stem vowel is realised) and that the reasoning in the main text appears to conflate abstract derivation with processing. The only answer that I am able to provide at this stage is that I endorse the view that the derivation of any one linguistic structure is expected to represent as closely as possible the processing that arguably takes place.

21 Despite the similarities between German and Yiddish, verbal paradigms in Yiddish appear to be determined by stem asymmetries, which would explain the language being V-to-T. 
The account of rich morphology that is defended in this paper as supporting the correlation between morphology and V-to-T movement signals therefore Icelandic as a V-to-T language, in accord with the more extended trend in the literature, and German as non-V-to-T, despite German sharing with Icelandic a similar amount of agreement morphology. As observed in section 3, there do not abound in the recent literature analyses linking together verbal morphology and V-to-T in German, which is very possibly due to German being SOV. On the other hand, Vikner (2005) argues that the language is non-V-to-T basing his argument upon independent evidence. The present analysis of $\mathrm{V}$-to- $\mathrm{T}$ is in accord with German as a non-V-to-T language. I turn to $\mathrm{OE}$ in the following Section.

\subsection{Morphological richness as provoked by the stem segment: The case of $\mathrm{OE}$}

In the present section I focus on $\mathrm{OE}$ with an aim to show that this language is akin to Romance or to modern Icelandic in the sense that a stem or thematic vowel segment imposes morphological asymmetries across the various tenses. Being able to implement on OE the same kind of analysis as was implemented on Spanish or Icelandic in the sections immediately above is actually one of the major purposes of the investigation, since it contributes in a relevant way to the idea that all Germanic languages had a V-to-T status in their older periods.

Now, as described in traditional philological studies like Wright \& Wright (1925), Mitchell (1968), or Moore \& Knott (1971), and also in more recent widely-known works like Lass (1992: 126-127), or Hogg (1992:157ff.), weak verbs in $\mathrm{OE}$ attend to a division into so-called Class I, characterised by a geminated consonant and the loss of an original stem or thematic vowel $-i$ - from West Germanic, and Class II, which retains a thematic vowel -o- from the cited West Germanic ancestor. Further, there is a small group of verbs forming a subclass within Class I, where the $-r$ - consonant that ends the stem syllable shows no gemination (verbs like e.g. nerian 'save'), and which is illustrated in (30) below as Class I(b). As for the verb hieran 'hear', which figures together with trymman 'strengthen' under Class I(a), this illustrates one type of asymmetry or variation that is not actually relevant for the analysis defended in this paper - see below in this section - and this is why no segmentation of the corresponding forms are featured in (30).

$$
\text { Old English }
$$

Class I(a)

$$
\text { trymman 'strengthen' }
$$

Present Past

1 psn sg

2 psn sg trymm- $\varnothing-\mathrm{e}$

trym-Ø-est trym- $\varnothing$-ed-e

trym-Ø-ed-est

\begin{tabular}{llll}
\multicolumn{2}{c}{ hieran 'hear' } & \multicolumn{2}{c}{ nerian 'save' } \\
Present & Past & Present & Past \\
hiere & hierde & neri- $\varnothing$-e & ner- $\varnothing$-ed-e \\
hierst & hierdest & ner- $Ø$-est & ner- $Ø$-ed-est
\end{tabular}




\begin{tabular}{|c|c|c|c|c|c|c|}
\hline & trym-Ø-ep & trym-Ø-ed-e & hierp & hierde & ner-Ø-ep & ner-Ø-ed-e \\
\hline$n_{1}$ & trymm- $\varnothing-\mathrm{ap}$ & trym-Ø-ed-on & hierap & hierdon & neri-Ø-ap & ner-Ø-ed-on \\
\hline $\operatorname{psn} p$ & trymm-Ø-ap & trym- $\varnothing$-ed-on & hierap & hierdon & neri- $\varnothing$-ap & ner-Ø-ed-on \\
\hline $3 \mathrm{psn} \mathrm{pl}$ & trymm- $\varnothing-\mathrm{ap}$ & trym- $\varnothing$-ed-on & hierap & hierdon & neri- $\varnothing$-ap & ner-Ø-ed-on \\
\hline
\end{tabular}

\section{Class II}

lufian 'love

Present Past

1 psn sg luf-i-e luf-o-d-e

2 psn sg luf-a-st luf-o-d-est

3 psn sg luf-a-p luf-o-d-e

$1 \mathrm{psn}$ pl luf-i-ap luf-o-d-on

$2 \mathrm{psn} \mathrm{pl}$ luf-i-ap luf-o-d-on

$3 \mathrm{psn}$ pl luf-i-ap luf-o-d-on

It must be noted that the above description is still an over-simplification of the whole set of $\mathrm{OE}$ weak verbs, since it is of course possible to acknowledge two further groups: on the one hand, the subgroup of verbs within Class I which have umlaut or front mutation originally only in the present but not in the past (note sècan/sohte 'seek', tellan/tealde 'tell'), and also a group of four well-

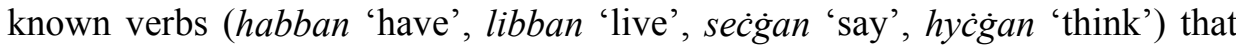
can be so considered to form Class III, and that are characterised by variation between mutated and non-mutated vowels, or geminated and non-geminated consonants. Nevertheless, the core of the present proposal of V-to-T is already contained in the set of forms illustrated in (30).

The proposal in question consists in that the speaker of OE, the same as the Spanish speaker or the speaker of Icelandic, must be able to compute the vocalic segment that figures between the root and the tense and/or agreement segment of Class II verbs. Though only Present and Past Indicative are illustrated in (30), Present and Past Subjunctive, and Imperative follow the same pattern the reader is referred to e.g. Hogg (1992: 159-161) for an illustration of the relevant forms. In a parallel fashion then to the statement in (19) as regards the Spanish paradigm in Section 4.1 above, or the statement in (29) relative to the paradigm in Icelandic in Section 4.2, the key aspect of the paradigm of OE regular verbs that, as the present discussion would like to contend, is at the base of the V-to-T phenomenon, is the asymmetry in (31) below.

(31) A stem vowel figures in the tenses forming the paradigm of Class II verbs but not so in the tenses of the paradigms of Class I verbs 
One example of the effect of the asymmetry described in (31) is that $3 \mathrm{psn} \mathrm{pl}$ of lufian of Present Indicative is lufiab while the corresponding form for a verb like trymman is trymmap. Also, short-stemmed verbs in Class I(b) (nerian) form their Past as nerede, as opposed to the Past form lufode, which corresponds to verbs of Class II (lufian). It must be noted that verbs like nerian feature a very similar medial sound as compared to verbs like lufian, though the former is a $/ \mathrm{j} /$ whereas the latter is a $/ 1 /$. Using this clue, the speaker must be able to build the segments corresponding to the stem vowel, tense, and agreement.

As stated in (31), Class II is the only one that features a stem or thematic vowel -o-, which is realised as such in Past Indicative but which in Present Indicative appears as $-i$ - in all persons except $2 \mathrm{sg}$ and $3 \mathrm{sg}$, where it is $-a$-. That is why the Past of lufian is divided in (30) above into four overt segments, whereas in all verbs under Class I figures a symbol - $\varnothing$ - for the corresponding segment. As for Present Indicative, lufian is divided into three segments, given the generalised non-overt status of the tense segment for the present of Germanic verbs. As will be recalled from the description of the other languages, the cited non-overt status has been considered here to be ambiguous between - $\varnothing$ - or non-existent. For the sake of completeness, and the same as was done for Spanish, English, German, and Icelandic in Sections 4.1-4.2 above, in (32) below are illustrated the cited two possible ways of analysing the segment corresponding to Present tense - the one appearing to the left of the double slash features the tense segment as present though null, and the one appearing to the right, which coincides with that in (30) above, considers that no such segment is the case at all.

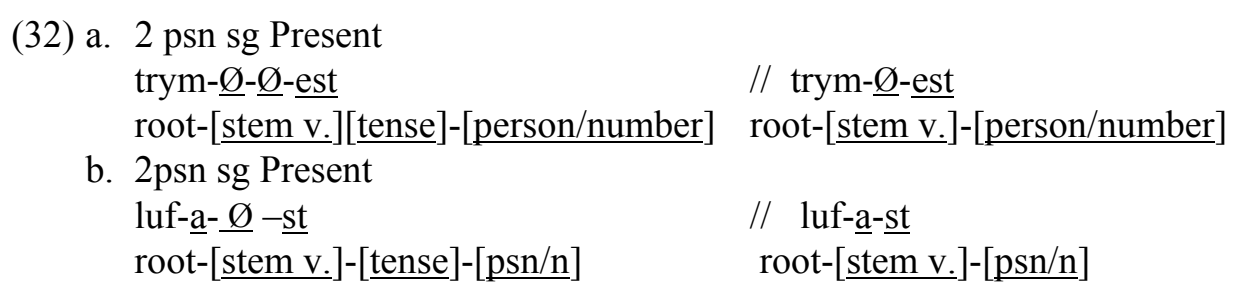

Lastly as regards the description of the forms listed in (30), I would like to observe that, in a similar fashion to Spanish or to Icelandic or otherwise German, the $\mathrm{OE}$ verbal paradigm is also characterised by more or less numerous allomorphic asymmetries or variations that are not nevertheless relevant for the present discussion. I am referring to the loss of $-e$ - of the agreement segment in 2 and 3 psn sg of Present, or the loss of -e- of the tense segment in all persons of Past of several verbs in Class I like hieran 'hear' above. Apart from the cited syncopated -e-, assimilation between consonants can also apply. This explains such forms as hierst, hierp, or hierde in (30) above, or also the Past forms cēpte and sette from cēpan 'keep' and settan 'set', respectively. 
All in all then, OE can be considered akin to Romance, or also to a modern Germanic language like Icelandic, as regards the division of its verbal paradigms into productive stem classes, which is contended in this paper to be the trigger of V-to-T. The morphological variation that is provoked by the stem or thematic vowel in a language like $\mathrm{OE}$ is not of course as wide-ranging as it is in Spanish, which is due to the smaller number of stem or thematic vowels in OE, and also the smaller number of tenses. However, the idea defended here for the general pattern to be that the stem or thematic vowel determines asymmetries in the overall composition of verbal forms can be applied both to Spanish and to $\mathrm{OE}$, and likewise to Icelandic. Further, since the present discussion endorses the theory that all Germanic languages in their old periods used to be V-to-T languages, I will close the present section by observing that, in a similar fashion to OE, both Old Norse (ON), as the precursor of modern Icelandic, and Old High German (OHG), as the precursor of modern German, have their verbal paradigms modelled around the presence of a stem or thematic vowel. Due to lack of space, I will restrict myself here to referring the reader to Faarlund (2004: 45ff.) and Wright (1906: 71ff.), respectively. In Section 5 immediately below, I provide a minimalist account of the V-to-T phenomenon, where I identify the stem or thematic vowel segment with a $v$-feature that $\mathrm{T}$ must value.

5. The morphological trigger of V-to-T movement: A minimalist syntax account

Chomsky $(1995,2000,2001)$ postulates that the linguistic component known as core or narrow syntax proceeds through the operations Merge and Agree, where the former consists in the combination of two syntactic units from the Lexicon/Numeration (external Merge) in order to form a new syntactic unit, and the latter (Agree) consists in that an element that acts as a Probe searches for a Goal, which it must c-command, in order to value formal features.

Two types of features typically involved in the approaches to V-to-T movement offered in the literature are $\varphi$-features on the one hand, and $\tau$-features on the other. $\varphi$-features could be roughly defined as the abstract counterpart of overtly realised agreement markers, and similarly $\tau$-features are the abstract counterpart of overtly realized tense markers. Further, subject-verb agreement is typically directly connected with nominative Case: DPs in subject position are argued to bear nominative Case.

Features are characterised based on the properties of valuation and of interpretability. Chomsky (2001: 5) couples together the properties of feature valuation and feature interpretability through positing that a feature is uninterpretable "if and only if it is also an unvalued feature." In this framework, it is the interpretability of features, that is, the capacity that a feature has to contribute meaning to the lexical item it belongs to, and eventually to the sentence as a whole, 
that drives a derivation. Computation of a linguistic sequence must converge at all interfaces, which means that if any uninterpretable feature is left unvalued at the interface between core syntax and the external systems, this will lead to the crash of the derivation. Further, the valuation of features will entail the movement of the Goal (more properly, internal Merge) in case the Probe has an EPP feature or property. If there is no such EPP feature on the part of the Probe, then the valuation of features (that is, Agree between Probe and Goal) will take place without movement. Incidentally, the cited EPP feature or property - whose origin is in the classical Extended Projection Principle of Government \& Binding theory - is postulated as a substitute of so-called strong features as based on rich morphology.

Chomsky $(2000,2001)$ postulates an Agree relation between the uninterpretable $\varphi$-features of $\mathrm{T}$ and their interpretable counterparts on DP, as a result of which the agreement on the verb is licensed, and also the nominative Case on DP. Nevertheless, $\varphi$-features are not analysed as the trigger of V-to-T in this framework, the reason for this being very possibly the ever-increasing acknowledgment in the general literature of the failure of the connection between rich/poor agreement and presence/absence of V-to- $\mathrm{T}$ (let us recall the critique of the RAH reported in Section 1 of the paper). Neither can the $\tau$-features on $T$ be held as the ones driving V-to-T movement, since the cited $\tau$-features are interpretable on $\mathrm{T}$ itself: given the biconditional between feature valuation and feature interpretability postulated in Chomsky (2001) (see immediately above in this section), only uninterpretable features can act as a Probe.

Chomsky (1995) entertains the hypothesis that $\mathrm{T}$ might have a V-feature to value against $v$ - that is, the position that the verb moves to after merging on $\mathrm{V}$ from the Lexicon, and that is responsible for the projection of the external argument within the verbal phrase. T's V-feature would be the one triggering Vto-T movement in case the relevant feature has an EPP property. The major puzzle would nevertheless arise why such a feature would have the cited EPP property for $\mathrm{V}$-to-T languages but not for non-V-to-T languages.

Problems relative to c-command, the Extension Condition, or the proper identification of the trigger lead Chomsky (2001) to suggesting that head movement (and V-to-T is of course a type of head movement) should perhaps be rejected as a core or narrow syntax phenomenon and should in turn be analysed as a $\mathrm{P}$ (honetic) $\mathrm{F}$ (orm) phenomenon, a proposal that was already present in Chomsky (1995). The reader is referred to the evaluation chapter by Roberts (2011) for a full description of this approach and also of other approaches that have been proposed in the literature in the wake of Chomsky (2001). 
Pesetsky \& Torrego (2004/2007) reject the biconditional established in Chomsky (2001) between valuation of features and their interpretability, and propose that each of these properties works independently of the other. In the authors' approach, the property of interpretability can be described as above, that is, as the semantic contribution that the feature in question makes to the item that bears it. As for feature valuation, Pesetsky \& Torrego analyse this as the capacity of any given item to come from the Lexicon already specified for that property - in which case the feature in question is valued on that item - or otherwise as the necessity of an item to borrow that property from another item - in which case the feature is unvalued on the borrowing item. A consequence of this is that e.g. the $\tau$-features of $\mathrm{T}$, which are interpretable on this head, can nevertheless act as a Probe for $v$ since such features are themselves unvalued on $\mathrm{T}$ but valued on $v$.

Pesetsky \& Torrego (2004/2007) reject the idea that subject agreement and nominative Case are the result of the licensing of $\varphi$-features (which should be uninterpretable on T and interpretable on DP, as in Chomsky 2000, 2001) and propose instead that an Agree relation between T, DP, and $v$ takes place that hinges around the $\tau$-features that are interpretable but unvalued on $\mathrm{T}$, uninterpretable and unvalued on DP, and uninterpretable and valued on $v$. The authors argue specifically that the Agree relation between T, $v$, and DP can entail either the raising of DP into Spec, $\mathrm{T}$, in the case that $\mathrm{T}$ triggers phrasal movement, or otherwise it can entail the raising of $v$ into $\mathrm{T}$, that is, $\mathrm{V}$-to-T movement, in which case $\mathrm{T}$ triggers head movement (as in Alexiadou \& Anagnostopoulou 1998). However, the authors admit that the relevant account cannot explain why $\mathrm{T}$ does not trigger head movement in e.g. English. It must be highlighted then that, in a similar way to Chomsky (2000, 2001), V-to-T movement does not appear to be justified in a full explanatory way in Pesetsky \& Torrego's framework.

The approach to V-to-T that is proposed in Section 5.1 immediately below maintains that the licensing of $\varphi$-features is part of subject-verb agreement, as in Chomsky $(2000,2001)$ and contra Pesetsky \& Torrego (2004/2007), but it does endorse Pesetsky \& Torrego's dissociation between feature interpretability on the one hand and feature valuation on the other.

\subsection{The present proposal of $\mathrm{V}$-to-T as a core syntax phenomenon}

In Sections 4.1-4.3 I have argued that the key concept to understand the phenomenon of V-to-T is that of productive verb class as based upon a thematic or stem vowel segment or marker. The idea that I have defended is that the thematic or stem vowel is the cause of morphological variations or asymmetries across tenses in Spanish (as a representative of Romance), or also in a modern Ger- 
manic language like Icelandic, and that the same situation can serve to characterise the ancestor of the English language, namely OE. In the present section my aim is to identify the cited stem or thematic vowel segment or marker with a specific kind of formal feature within minimalist theory.

As observed in Section 5 immediately above, an important trend within minimalist theory (starting from Chomsky 1995) argues that head movement is not a narrow syntax phenomenon but a PF phenomenon. By contrast with this, I endorse the view that verbal morphology is part of core or narrow syntax, and that $\mathrm{V}$-to-T is a core or narrow syntax phenomenon, as had been the classical view within generative theory.

I would like to argue that the abstract correlate of the stem or thematic vowel segment is a $v$ feature that $\mathrm{T}$ must value: T's $v$-feature, which, as just suggested, is unvalued on $\mathrm{T}$, would be taken therefore as the trigger of $\mathrm{V}$-to-T. The computation of features between T, $v$, and DP is shown in the tree-diagrams in (33), and the order of implementation is discussed immediately afterwards. It must be observed that other features, like e.g. those that correspond to the processing of the internal argument or object, are ignored here, since these are not relevant for the discussion.

The derivation of a transitive sequence begins, as standardly assumed, with the external Merge of $\mathrm{V}$ and $\mathrm{O}$, thereby forming VP, and with the subsequent Merge of $v$ and an external argument or S(ubject), which form $v \mathrm{P}$. Next, $\mathrm{T}$ is merged with $v \mathrm{P}$. Now, the licensing of $\varphi$-features (which correspond to person/number) begins already on external Merge of $\mathrm{S}$ in Spec of $v$, since such features are valued and interpretable on S itself, and they are to get valued and interpreted on the $v$ head. Such $\varphi$-features are analysed here as c-selectional features, for which I assume the view in Adger (2004: 84ff.) or Panagiotidis (2014: 120ff.) that c-selectional features are ones valued on external Merge between sister constituents: the $\varphi$-features in question correspond to notation 1 in boldface in the tree-diagrams in (33)).

The valuation of $\varphi$-features cannot be completed until the valuation of $\tau$ features applies (see numbers 4 and 5 in the tree-diagrams), which in turn must await the valuation of the $v$-feature that, as postulated here, T must value against $v$ (see number 3 in the tree-diagrams). 

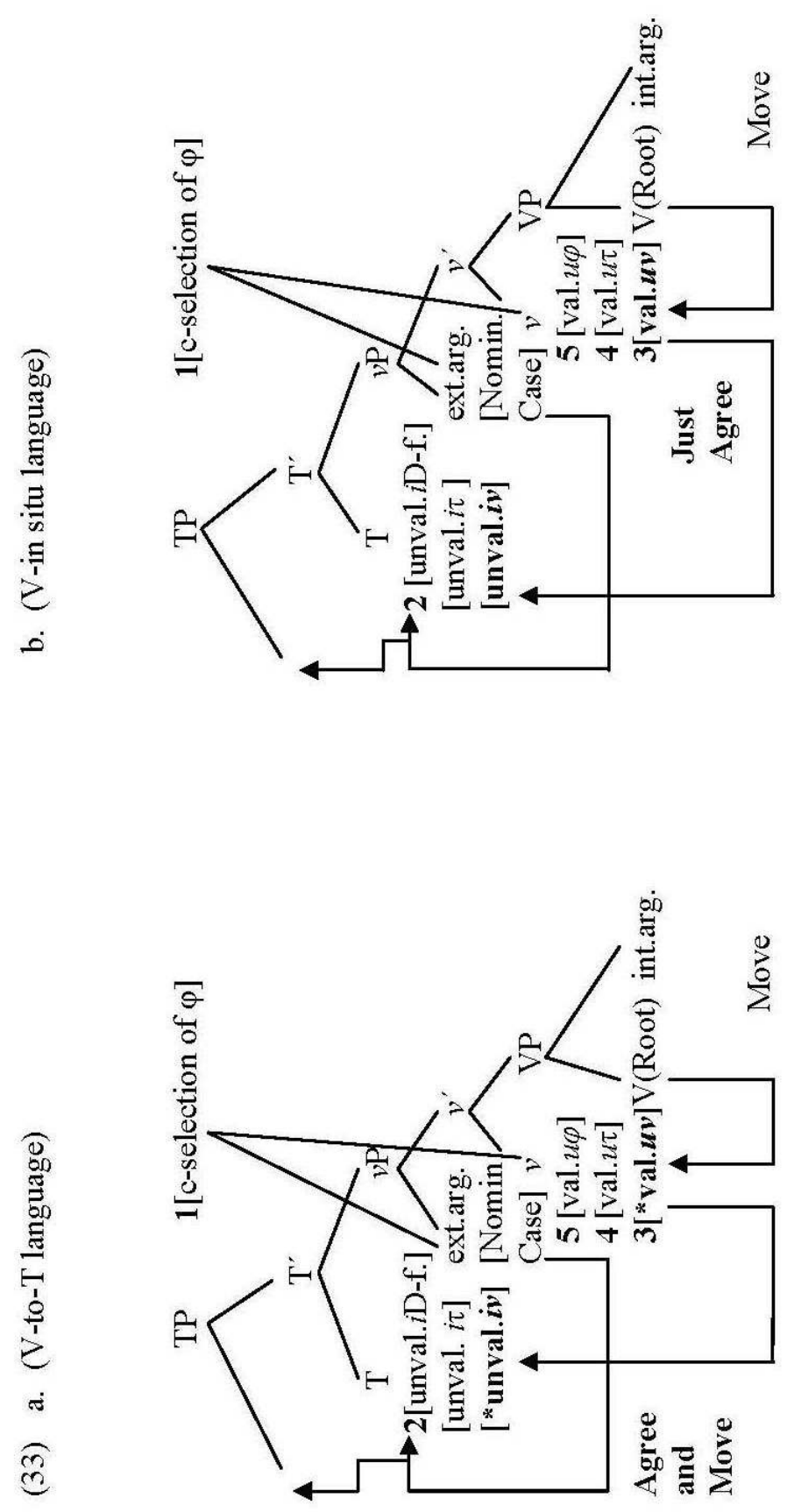
In effect, the proposal defended in this paper is that there is a $v$-feature that is interpretable and unvalued on $\mathrm{T}$, and uninterpretable and valued on $v$. The feature in question has a morphological correlate in the thematic or stem vowel segment, and is responsible for V-to-T movement whenever it is a strong feature: such is the case in the tree-diagram in (33a), where the arrow leading from [val.uv] to [unval.iv] is marked Agree and Move; by contrast, the corresponding arrow in the diagram for a $\mathrm{V}$-in situ language (33b) is marked Just Agree.

Now, as observed immediately above, the valuation of the $v$-feature applies before the valuation of $\tau-$ features, which in turn applies before the valuation of $\varphi$-features (let us recall the numeration 3-4-5 in the tree-diagrams). However, two processes apply before these, namely, the c-selection process of $\varphi$-features, which is marked $l$ on the tree-diagrams and which I referred to above in this section, and the process marked 2, which is relative to the feature that the head $\mathrm{T}$ is to value against $\mathrm{S}$ (ubject), and which I discuss briefly immediately below. After that, I will turn again to the order of computing between the $v$-feature, $\tau-$ features, and $\varphi$-features.

I adopt the hypothesis that $\mathrm{T}$ has a $\mathrm{D}$-feature, which is entertained in Chomsky $(2000,2001)$ in order to explain sequences in which Spec, $T$ is filled with existential there (There are problems with the computer, There arrived a stranger at the station). Such a D-feature is therefore responsible for the raising of there in the cited sequences, or indeed for the raising of any ordinary subject. The meaning or interpretation of the cited D-feature of $\mathrm{T}$ could be identified as subject of predication. As is well known, a correlation appears to exist between the rich $\varphi$-features as exhibited by $v$ and the obligatory or non-obligatory status of the rasing of S(ubject) to Spec,T: a language like e.g. English is defined in this sense as a non-null-subject language, since $\mathrm{S}$ must raise to Spec,T, whether a language like e.g. Spanish is a null-subject language, and likewise a language where S(ubject) does not have to raise to Spec,T obligatorily. As for nominative Case, its analysis is strictly speaking outside the scope of this paper, but there seems to be in principle no reason for not assuming that Case on DP is the counterpart of the D-feature on $\mathrm{T}^{22}$

The process of computing for a V-to-T language (tree-diagram (33a)) would thus be as follows. The valuation of c-selectional $\varphi$-features between $\mathrm{S}$ and $v$, which are sister constituents on external Merge, applies: see notation 1 [cselection of $\varphi$ ]. Then, $\mathrm{T}$ probes for $\mathrm{S}$ to value its $\mathrm{D}$-feature and $\mathrm{S}$ arguably val-

22 As is widely known, nominative Case on DP is the counterpart of $\varphi$-features on $\mathrm{T}$ in the framework of Chomsky $(2000,2001)$, a position that is criticised by Pesetsky \& Torrego (2004/2007), who in turn propose that the nominative Case on DP is a kind of $\tau$-feature on the nominal. 
ues its nominative Case - see notation 2 [unvalued, interpretable D-feature] in $\mathrm{Spec}, \mathrm{T}$, and the arrow that goes from [Nom. Case] under external argument to the cited Spec, T position. Subsequently, T probes $v$, another position that $\mathrm{T}$ ccommands, to value its $v$-feature, and $v$ raises up into $\mathrm{T}$, which is actually identified as V-to-T movement: see notation 3 going from [valued, uninterpretable $v$ ] under $v$ to [unvalued, interpretable $v$ ] under T. The corresponding arrow is marked Agree and Move, and V-to-T actually applies because of the morphological strength of the $v$-feature.

After this, T probes $v$ again to value T's $\tau$-features: note 4 on the tree-diagram, which corresponds to [valued, uninterpretable $\tau$ ] on $v$ and [unvalued, interpretable $\tau]$ on T. $v$ is actually on the same T head by now: since each node ccommands itself, then the condition of c-command between the Probe (T) and the Goal $(v)$ is satisfied. The derivation is completed with the valuation of $\varphi$-features, which applies on the same head $v$ while $T$ values the above-cited $\tau$-features against $v$ : note 5 [valued, uninterpretable $\varphi$ ] on $v$. Such $\varphi$-feature valuation has already started with the valuation of c-selectional features between $\mathrm{S}$ and $v$, and is eventually a by-product of the valuation of $\tau$-features by $T$.

Now, as discussed in Sections 4.1-4.3 of the paper, the morphological explanation of the very movement of $\mathrm{V}$-to- $\mathrm{T}$ lies in the productive type of stem or thematic vowel that is found in Romance, in a modern Germanic language like Icelandic, or in $\mathrm{OE}$ (and arguably in old Germanic languages in general). Given the location of the theme vowel in between the root and the tense marker, and since the morphological variation that has been described for Spanish, Icelandic, or OE in the above-cited Sections 4.1-4.3 does not typically affect the root or otherwise the agreement segment - that is, the segment or marker corresponding to person/number - but the middle part of the verbal form, then it is logically concluded that the valuation of T's $v$-feature must take place before the valuation of $\tau$-features. This explains the sequence 3-4 in the tree. As for the valuation of $\varphi$-features to depend on that of $\tau-$ features - that is, as regards the order 4-5 - the explanation of this is also contained in the discussion in Sections 4.1-4.3.

Thus, in a language like e.g. Spanish (see Section 4.1 above), with three stem verbal classes and a large number of tenses, the set of agreement markers can be said to be roughly: $-\varnothing$ or $-o /-\varnothing,-s,-\varnothing,-m o s,-i s,-n$, and such would be the content of the initial c-selection process between $\mathrm{S}$ and $v$. However, there is variation in $1 \mathrm{psn}$ sg and also in $2 \mathrm{psn}$ sg, which is determined by the tense in question or, in other words, by the valuation of $\tau$-features between $\mathrm{T}$ and $v$. As for $\mathrm{OE}$ (Section 4.3), there is also a very small amount of variation among $\varphi-$ features, as in Spanish, though it also depends on $\tau$-features (which in turn depend on the $v$-feature, that is, on corresponding thematic classes). Specifically, the OE agreement markers in Indicative for Class I are $-e,-e s t-e p,-a p$ for Pre- 
sent, and $-e,-e s t,-e,-o n$ for Past. And for Class II they are $-e,-s t,-b,-a p$ for Present, and $-e,-e s t,-e,-o n$ for Past.

By contrast with Spanish, OE, or Icelandic, no V-to-T takes place in languages like (modern) English, German, or the Mainland Scandinavian languages, which means that T's $v$-feature is weak, or put another way, T's $v$-feature does not correlate with rich morphology in the sense that there is no stem or thematic vowel. Also, it can be the case that the stem or thematic vowel is not productive, that is, it can possibly be historically part of the segment where tense and/or agreement markers are added, but it does not provoke morphological variations or asymmetries, and therefore the verbal paradigm of the language in question cannot be considered to be divided into thematic classes. The computation of features in these non-V-to- $\mathrm{T}$ languages, which corresponds to the tree-diagram (33b), is identical to that in V-to-T languages (tree-diagram (33a)), except for the valuation of T's $v$-feature. On this occasion, such valuation is carried out with the verbal form staying put in situ, that is, without movement: this is why the arrow in (33b) leading from 3 [valued, uninterpretable v] to [unvalued, interpretable $v$ ] is marked Just Agree. Though a language like German is much richer than (modern) English as regards $\varphi$-features - let us recall corresponding paradigms in Section 4.2 above - this contrast has nothing to do with both languages being non-V-to-T, since this property is related to the $v$-feature of $\mathrm{T}$, which would behave in the same way in English or in German.

Lastly, aside from the contrast that results from the strong vs. weak status of the $v$-feature in $\mathrm{V}$-to-T languages vs. $\mathrm{V}$-in situ languages, the sequence of computing between the cited $v$-feature, $\tau$-features, and $\varphi$-features applies in both language types alike. Thus, in a language like (contemporary) English (Section 4.2 ), the initial c-selection process establishes $-\varnothing$ or otherwise -ed for all persons, except the $3 \mathrm{psn} \mathrm{sg}$, where it is $-s$ or $-e d$. Which of these $\varphi-$ features is eventually valued will depend on whether the corresponding $\tau$-features are Present or Past. The order 3-4-5 is thus as in (33a), except for the fact that step 3 does not affect the segments that are eventually valued in steps 4 and 5 .

I would like to refer to the characterisation of T's $v$-feature - which is the one responsible for $\mathrm{V}$-to- $\mathrm{T}$ on this account - as unvalued on $\mathrm{T}$ but interpretable. For the feature in question to be unvalued on $\mathrm{T}$ means that $\mathrm{T}$ must get its value from the value the Lexicon provides $v$ with, which seems to be completely logical. Incidentally, the same reasoning applies to the $\tau$-features that $\mathrm{T}$ must value against $v$ (which is a theory adopted from Pesetsky \& Torrego 2004/2007 - see Section 5 above). As for the claim that the $v$-feature on $\mathrm{T}$ is interpretable, I would like to suggest that this is justified on the grounds that the feature in question gives rise to a productive set of stem or thematic verb classes. 
5.2. Three other morphology-based accounts of V-to- $\mathrm{T}$ in the current literature

In this section I describe briefly three analyses in the recent literature that make use of rich morphology in order to explain V-to-T. These are: Bobaljik \& Thráinsson (1998), Biberauer \& Roberts (2008), and Koeneman \& Zeijlstra (2014).

Bobaljik \& Thráinsson (1998) make use of a split I(nflection)P(hrase), namely the seminal type of configuration introduced by Pollock (1989) and consisting of an AgrP and a TP, at a time when the trend in syntactic theory is to contend that a unique TP projection is in charge of licensing both tense and agreement morphology. The authors argue that a split IP, as in (34a), makes it possible for agreement segments to be located in a differentiated way from tense segments. By contrast, the structural configuration of $\mathrm{V}$-in situ languages would feature a unique inflectional head I, as in (34b).

(34) a

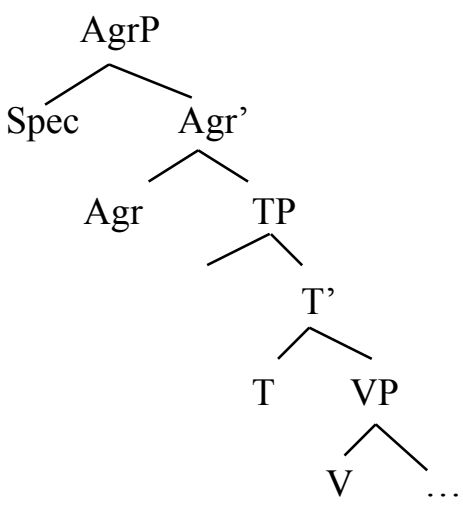

b.

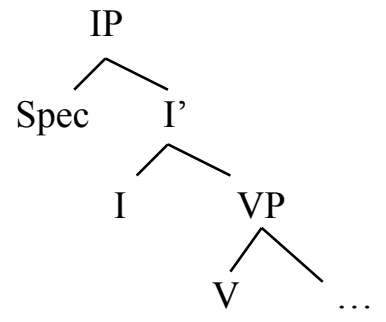

The core of Bobaljik \& Thráinsson's account is that the verb (V) has no possibility to check its $\varphi$-features against Agr other than raising first to T, which means that they endorse the idea that the Agree mechanism cannot apply across intervening heads, against standard assumptions in syntactic theory. In their analysis, whenever $\mathrm{V}-$ or rather $v$ in a more precise type of configuration - is in the position of complement to I (as happens in (34b)), then $\mathrm{V}$ itself does not need to move to I in order to check $\varphi$-features and/or $\tau$-features, and stays put in $v$. Further, Bobaljik \& Thráinsson argue that a split IP is what makes V-to-T possible, but that a language with a split IP may decide whether to apply V-to$\mathrm{T}$, as Icelandic does, or not, as the descendant version of Faroese. Thus the authors establish a connection between the division of IP into AgrP and TP on the one hand, and rich morphology on the other, though not between movement and rich morphology. 
Bobaljik (2002) maintains the analysis of a split IP as the syntactic property licensing rich morphology, and he goes on to argue that rich morphology (that is, distinct morphemes for agreement and tense) is licensed by the same syntactic property that triggers V-to-T movement, namely a split IP. Bobaljik aims to be able to acknowledge that rich morphology means V-to-T on a general basis, and for that he changes their previous segmentation of Faroese verbal forms: he concludes from the new segmentation that the recently-developed Faroese language has poor morphology, and is therefore a $\mathrm{V}$-in situ language.

Now, despite the insight of the rationale of an account like Bobaljik \& Thráinsson (1998), and despite Bobaljik's (2002) detailed and valuable observations about the place of morphology in the syntax, I would like to hightlight very briefly what appear to be three important weak aspects of the authors' account. The first two aspects are actually cited in Koeneman \& Zeijlstra's (2014) work, to be described below in this section: one is, as noted above, for Agree not to be able to take place in their account across intervening heads, which runs counter to common views in the literature; the other is that, if the morphological analysis that Bobaljik (2002) implements on the new version of Faroese is likewise implemented on Icelandic, then it could as well be taken as a V-in situ language, which is not a welcome result at all.

Aside from the above criticisms, I would like to refer to German as a major weak point in the overall discussion by the authors, which they themselves acknowledge. In effect, the separation of agreement segments and tense segments that Bobaljik \& Thráinsson postulate in their account of Icelandic must necessarily render German as a V-to-T language, which leads them to stating that the issue in question remains open to debate.

As for the second approach that I would like to mention in this section, namely Biberauer \& Roberts (2008), this does cover German though not in a satisfactory way from the perspective of the present discussion, as I will specify immediately below. The authors adhere in the first place to the current trend in minimalist syntax that head movement is not a core or narrow syntax phenomenon, and argue that so-called V-to-T movement (whenever it applies) is actually not an instance of head movement, but of a compound $[\mathrm{V}+\mathrm{T}]$. Aside from this theoryinternal issue, the core of Biberauer \& Roberts' argument is that the opposition between V-to-T movement languages, as are Romance languages, and V-in situ languages, as is the case of Germanic, lies in the far richer number of synthetic verbal tenses existing in Romance as opposed to Germanic. In effect, it is a wellknown fact that Germanic languages have just a present tense and a past or preterite, whereas Romance additionally distinguishes a perfective past and an imperfective past, a future tense, and also a conditional (let us recall the very paradigms in Sections 4.1-4.2). Thus the authors argue that verbal forms in Romance come 
inflected from the Lexicon, and corresponding features are satisfied in core or narrow syntax through Agree and Move, hence the occurrence of verb movement. In other words, Biberauer \& Roberts postulate that the abundance of synthetic tenses has as a consequence that corresponding $\tau$-features are active in core syntax and provoke verb movement: in their account, it is richness of T's $\tau$-features that causes $\mathrm{V}$-to- $\mathrm{T}$, but exactly richness of $\tau$-features as a gross quantitative property of the overall verbal lexicon of a language.

In contrast to Biberauer \& Roberts (2008), the type of morphological richness that is the cause of $\mathrm{V}$-to- $\mathrm{T}$ in the account proposed here does not lie in the number of synthetic verbal tenses of any given language, but in the number of variations or asymmetries across tenses, whether these (that is, tenses) are numerous, as in Romance, or not, as in Icelandic or in OE. In other words, in the account proposed here, rich morphology relates to the inner build-up of verbal paradigms in the language, and not to number of tenses in the paradigms.

As suggested, Biberauer \& Roberts' approach does presuppose that Germanic languages used to be non-V-to-T from their old periods, since the smaller number of synthetic tenses in Germanic as compared to Romance can be traced back to Proto-Germanic and Proto-Romance times. This presupposition is actually dealt with by the authors in Biberauer \& Roberts (2005/2008), where they argue that the V-to-T mechanism exhibited by English in the ME period is due to a reanalysis of V2 structures with the subject in initial position - the reader is referred to (11) in Section 2.1 above. The loss of V-to-T in the subsequent EMnE period would be the result, according to the authors, of the scarcity of tenses of the English paradigm described immediately above. As has been noted in section 1 of the paper, the analysis of V-to-T defended here is in accord with Germanic languages being $\mathrm{V}$-to-T in their older periods.

The third account that I would like to refer to in the present section is Koeneman \& Zeijlstra (2014), who answer back to criticism of either a strong or a weak version of the RAH, and contend that there does exist a full correlation between verb movement and subject agreement. As observed in Section 1, the specific use of the diagnostic tests like the position of adverbs or negation, and also the differentiation between V-to-T and V-to-C (or V2) turn out to be crucial for any given approach to acknowledge a language as $\mathrm{V}$-to- $\mathrm{T}$ or $\mathrm{V}$-in situ, and it seems to be essential to reach consensus on this matter. Focusing on Koeneman \& Zeijlstra's analysis, the authors make use of the feature-checking mechanism of the 1990s between a head and the element in its Spec position, and they also explain the specific mechanism of $\mathrm{V}$-to- $\mathrm{T}$ by means of a construct of the decade of the 1980s and 1990s, as described below. But the core element of their account is that the authors reverse the domain of tense as understood in current syntactic theory, since they argue that it is checked within the $v \mathrm{P}$, which allows them to relocate agreement, in the form of $\operatorname{Arg}$ (ument) $P$ (hrase), to the 
position it used to occupy in GB times, that is, at the top of sentence structure: see the tree-diagram in (35).

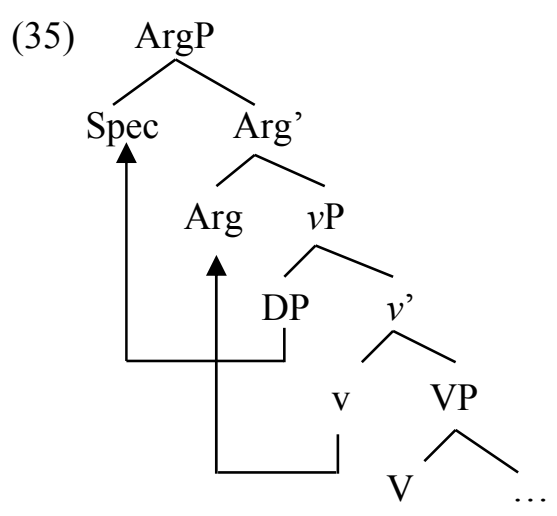

Specifically, Koeneman \& Zeijlstra (2014) contend that $\varphi$-features make up a formal superfeature called $\arg ($ ument), which covers in turn the features [speaker], [participant] and [plural]: in the authors' view, the minimal necessary features to form pronouns. Briefly put, their argument is that the uninterpretable argument-feature must be checked by an element in its Spec position that has the corresponding interpretable feature, hence the raising of the DP subject to Spec,Arg. Further, the feature [argument] in the head Arg is itself an affix and as such it needs to end up in a position adjacent to the verb. This means that verb movement, in their approach V-to-Arg movement, is triggered by the socalled Stray Affix Filter initially postulated in the 1980s, as noted above. Whether the verb moves in the syntactic component or post-syntactically, Koeneman \& Zeijlstra's analysis is open to either mechanism. In sum, those languages that have a formal feature [argument] - that is, those languages that have verbal affixes indicating the above-mentioned concepts of speakerhood, participanthood, and plurality - must project the feature in question in a functional projection $\operatorname{ArgP}$ as shown in (35): such languages will be verb-moving languages.

Now, I would like to observe in the first place that in order to acknowledge the virtues or the superiority of Koeneman \& Zeijlstra's account over any other account, it should be necessary to analyse in detail whether their analysis of tense inflection as being irrelevant for verb movement is tenable at all: the authors resort to rejecting the projection of a Tense phrase on top of $v \mathrm{P}$ since, in the case of e.g. English, this should mean that the projection in question hosts an -ed affix, which would function in exactly the same way as agreement affixes do for verbmoving languages, and this should predict, in the wrong way, verb movement for 
this language. On the other hand, as is well known, and as I have tried to show at least partially in the brief review of Chomsky $(2000,2001)$ and of Pesetsky \& Torrego (2004/2007) in Section 5 above, it is the location or the licensing of $\varphi-$ features - and not of $\tau$-features - that appears to be controversial in syntactic theory. In this sense, I would like to recall that in the approach that I propose in this paper $\varphi$-features belong initially within the $v \mathrm{P}$, since it is $v$ that must value $\varphi-$ features properly speaking, though it does so eventually with the help of $\mathrm{T}$, more specifically at the point when $\mathrm{T}$ values its $\tau$-features. I would like to emphasise that the order of computation that I defended in Section 5.1 above - namely, the $v$-feature first, followed by $\tau$-features, and lastly $\varphi$-features - is one that can be ratified from the typical segmentation of a verbal form, and also from an analysis of which segments determine which segments.

All in all, an analysis of tense in the terms proposed by Koeneman \& Zeijlstra (2014) is out of the scope of the present discussion, but it is doubtful whether rejecting TP as a component of the clausal spine has a solid base at all. Also, as observed already, in order to be able to know whether it is possible to acknowledge certain languages as $\mathrm{V}$-to- $\mathrm{T}$ or $\mathrm{V}$-in situ, it seems necessary to put together and confront in an uniform way the various positions relative to the diagnostic tests for V-to-T, and to when or whether V-to-T can be discerned from V2 that are defended in recent works like e.g. Thráinsson (2010), Koeneman \& Zeijlstra (2014) itself, or the studies cited by these two. Pending such caveats, I would like to put an end to this brief review of Koeneman \& Zeijlstra (2014) by criticising the authors' view on Faroese and also on German.

The authors' analysis of the recently developed variety of Faroese relies on acknowledging the lack of the feature [participant], which consists in the lack of distinction in the segment or marker for $2 \mathrm{psn}$ sg or pl as compared to $3 \mathrm{psn}$ sg or $\mathrm{pl}$, with the result that the language does not project an $\mathrm{ArgP}$ on top of $\nu \mathrm{P}$ and no movement of the verb applies - let us recall that the latter should be V-to-Arg movement in the authors' approach. For Koeneman \& Zeijlstra then, for this language not to be verb-moving fits perfectly well with its not having a rich agreement morphology. However, the vernacular or original Faroese language has the same morphology though it has V-to-T (as argued by Heycock \& Sorace (2006), or Thráinsson (2010) among many others). Therefore, either there is a contradictory use of diagnostic tests, or there is a contradiction in the formulation of rich morphology that is provided by Koeneman \& Zeijlstra (2014).

As regards German, which is considered in this paper a very important language for the overall issue of V-to-T, Koeneman \& Zeijlstra (2014) choose to acknowledge German as head-final at the base, and from that point of view the authors' account of rich morphology in the language - which would effectively project a superfeature Argument - can simply not be falsified. The analysis of Koeneman \& Zeijlstra entails vacuous movement, which is actually a complete- 
ly valid option from a conceptual point of view. However, their analysis also entails obligatorily rejecting LCA theory (that is, a head-initial analysis), which I do not comply with. I think that, by contrast with Koeneman \& Zeijlstra (2014), the morphological analysis proposed here is a principled account of German as a V-in situ language.

\section{A summary of the proposal}

I have argued in this paper that the hypothesis that OE is a V-to- $\mathrm{T}$ language is a tenable one, and that V-to-T movement is the result of the licensing of a $v$ feature on $T$, which is unvalued but interpretable on $T$ itself, and which must be valued in core or narrow syntax. Such a feature that T must value against $v$ is the theoretical counterpart of the morphological segment that is known as the stem or thematic vowel and that, in V-to-T languages, gives rise to morphological variation or asymmetries across tenses, in case the feature itself is strong. In other words, the displacement of $\mathrm{V}$ (or rather $v$ ) to $\mathrm{T}$ would take place whenever the stem or thematic vowel segment, which is the morphological realisation of T's $v$-feature, results in productive stem verb classes in the language in question, and it arguably corresponds with a longer or more complex process of computation since such a $v$-feature must be processed in the mind/brain of speakers before the processing of $\tau$-features and/or $\varphi$-agreement features. More specifically, the syntactic computation of features in the derivation begins with the valuation of T's $v$-feature in the first place, though a process of c-selection of $\varphi$-features takes place between S(ubject) and $v$ on external Merge of these elements. Then, in case T's $v$-feature is strong - which correlates in the present approach with there being in the verbal paradigm a productive stem vowel segment - the verb raises to T. Subsequently, $\tau$-features are valued, since these are determined by the cited $v$-feature, and $\varphi$-features are valued, since these are in turn determined by $\tau$-features.

The analysis proposed of V-to-T, which is initially implemented on a Romance language like Spanish, renders a modern Germanic language like Icelandic also as V-to-T, but not German, which would agree with a widelyextended opinion in the current literature. Finally, the cited analysis is implemented on OE, the more general idea being for both Romance and Germanic languages to have been V-to-T from their oldest periods, but for Germanic languages to have stopped being V-to-T in their early modern periods (except arguably for Icelandic, Yiddish, and the vernacular Faroese language).

The present proposal has been contrasted with three well-known accounts in the recent literature on V-to-T which are similarly based on rich morphology, but each of a completely different kind, namely Bobaljik \& Thráinsson (1998), Biberauer \& Roberts (2008), and Koeneman \& Zeijlstra (2014). 
I defend the view that morphology is actually a factor determining the synchronic syntax of verbs (of the Indo-European languages), a situation that can be traced diachronically. The existence of languages with rich morphology and no V-to-T, and also of languages with poor morphology but with V-to-T does not contradict the correlation between rich morphology (in the way formulated here) and the V-to-T phenomenon, since there are arguably other factors governing word order in natural language: specifically, the former type of language is arguably to be explained by a distinct behaviour of adverbs, and the latter type would be replacing V2 with V-to-T movement.

\section{REFERENCES}

Adger, David. 2004. Core syntax: A Minimalist approach. Oxford \& New York: Oxford University Press.

Alexiadou, Artemis \& Elena Anagnostopoulou. 1998. Parameterizing Agr: Word order, verb movement and EPP-checking. Natural Language \& Linguistic Theory 16: 491-539.

Axel, Katrin. 2007. Studies on Old High German syntax: Left sentence periphery, verb placement and Verb-Second. Amsterdam: John Benjamins Publishing Company.

Bentzen, Kristine, Porbjörg Hróarsdóttir, Gunnar Hrafn Hrafnbjargarson \& Anna-Lena Wiklund. 2007a. Embedded V2 in Scandinavian: Empirical observations. Reykyavík: NORMS Verb Placement Workshop.

Bentzen, Kristine, Gunnar Hrafn Hrafnbjargarson, borbjörg Hróarsdóttir \& Anna-Lena Wiklund. 2007b. Extracting from V2. Working Papers in Scandinavian Syntax: 79: 119-128.

Biberauer, Theresa, Anders Holmberg \& Ian Roberts. 2008. Structure and linearization in disharmonic word orders. In Charles B. Chang \& Hannah J. Haynie (eds.), The proceedings of the 26th Western Coast Conference on Formal Linguistics, 96-104. Somerville, MA : Cascadilla Proceedings Project.

Biberauer, Theresa \& Ans van Kemenade. 2011. Subject positions and information-structural diversification in the history of English. Catalan Journal of Linguistics 10: 17-69.

Biberauer, Theresa \& Ian Roberts. 2005/2008. Subjects, Tense and verb movement in Germanic and Romance. Cambridge Occasional Papers in Linguistics 3: 24-43.

Biberauer, Theresa \& Ian Roberts. 2008. Cascading parameter changes: Internally-driven change in Middle and Early Modern English. In Thorhallur Eythórsson (ed.), Grammatical change and linguistic theory: The Rosendal Papers, 79-113. Amsterdam: John Benjamins.

Bobaljik, Jonathan D. 2002. Realizing Germanic inflection: Why morphology does not drive syntax. Journal of Comparative Germanic Linguistics 6: 129-167.

Bobaljik, Jonathan D. \& Hoskuldur Thráinsson. 1998. Two heads aren't always better than one. Syntax 1: 37-71.

Campbell, Alistair. 1959. Old English grammar. Oxford: Oxford University Press.

Chomsky, Noam. 1995. The Minimalist Program. Cambridge, MA: MIT Press.

Chomsky, Noam. 2000. Minimalist inquiries: The framework. In Roger Martin, David Michaels 
\& Juan Uriagereka (eds.), Step by step: Essays on Minimalist syntax in honour of Howard Lasnik, 89-156. Cambridge. MA: MIT Press.

Chomsky, Noam. 2001. Derivation by phase. In Michael Kenstowicz (ed.), Ken Hale: A life in language, 1-52. Cambridge, MA: MIT Press.

Danckaert, Lieven. 2012. Latin embedded clauses: The left periphery. John Benjamins Publishing: Amsterdam/Philadelphia.

Emonds, Joseph. 1978. The verbal complex V-V in French. Linguistic Inquiry 9, 151-175.

Eythórsson, Thorhallur. 1995. Verbal syntax in the Early Germanic languages. PhD dissertation, Cornell University.

Faarlund, Jan Terje. 2004. The syntax of Old Norse. Oxford: Oxford University Press.

Fischer, Olga. 2007. Morphosyntactic change: Functional and formal perspectives. Oxford: Oxford University Press.

Fischer, Olga, Ans van Kemenade, Willem Koopman \& Wim van der Wurff. 2000. The syntax of Early English. Cambridge: Cambridge University Press.

Haeberli, Eric. 2002a. Inflectional morphology and the loss of V2 in English. In David Lightfoot (ed.), Syntactic effects of morphological change, 88-106. Oxford: Oxford University Press.

Haeberli, Eric. 2002b. Observations on the loss of Verb Second in the History of English. In C. Jan-Wouter Zwart \& Werner Abraham (eds.), Studies in comparative Germanic syntax. Proceedings from the $15^{\text {th }}$ Workshop on comparative Germanic syntax, 245-272. Amsterdam \& Philadelphia: John Benjamins Publishing Company.

Haeberli, Eric. 2005. Clause type asymmetries in Old English and the syntax of verb movement. In Montserrat Batllori, M. Lluïsa Hernanz, Carme Picallo \& Francesc Roca (eds.), Grammaticalization and parametric variation, 267-283. Oxford: Oxford University Press.

Haider, Hubner. 2010. The syntax of German. Cambridge: Cambridge University Press.

Haider, Hubner. 2012. The VO-OV split of Germanic languages. The Journal of Comparative Germanic Linguistics 8: 1-53.

Han, Chung-hye. 2000. The evolution of do-support in English imperatives. In Susan Pintzuk, George Tsoulas \& Anthony Warner (eds.), Diachronic syntax: Models and mechanisms, 275-295. Oxford: Oxford University Press.

Heycock, Caroline \& Antonella Sorace. 2006. Verb movement in Faroese. New perspectives on an old question. Nordlyd 35: 1-16.

Hogg, Richard. 1992. Phonology and morphology. In Richard Hogg (ed.), The Cambridge history of the English language, vol. 1, 67-167. Cambridge: Cambridge University Press.

Holmberg, Anders \& Christer Platzack. 1988. On the role of inflection in Scandinavian syntax. Working Papers in Scandinavian Syntax 42: 25-42.

Kemenade, Ans van. 1987. Syntactic Case and morphological Case in the history of English. Dordrecht: Foris

Kemenade, Ans van. 1997. V2 and embedded topicalization in Old and Middle English. In Ans van Kemenade \& Nigel Vincent (eds.), Parameters of morphosyntactic change, 326352. Cambridge: Cambridge University Press.

Klima, Edward S. 1964. Negation in English. In Jerry A. Fodor \& Jerrold J. Katz (eds.). The structure of language, 246-323. New York: Prentice Hall.

Koeneman, Olaf \& Hedde Zeijlstra. 2014. The Rich Agreement Hypothesis rehabilitated. Linguistic Inquiry 45: 571-615.

Kosmeijer, Wim 1986. The status of the finite inflection in Icelandic and Swedish. Working Pa- 
pers in Scandinavian Syntax 26: 1-41.

Kroch, Anthony \& Ann Taylor. 1997. Verb movement in Old and Middle English: Dialect variation and language contact. In Ans van Kemenade \& Nigel Vincent (eds.), Parameters of morphosyntactic change, 297-325. Cambridge: Cambridge University Press.

Kroch, Anthony \& Ann Taylor. 2000. Verb-object order in early Middle English. In Susan Pintzuk, George Tsoulas \& Anthony Warner (eds.), Diachronic syntax: Models and mechanisms, 132-163. Oxford: Oxford University Press.

Lass, Roger. 1992. Phonology and morphology. In Norman Blake (ed.), The Cambridge history of the English language, vol. 2, 23-155. Cambridge: Cambridge University Press.

Ledgeway, Adam. 2012. From Latin to Romance: Morphosyntactic typology and change. Oxford: Oxford University Press.

Lightfoot, David. 1979. Principles of diachronic syntax. Cambridge: Cambridge University Press.

Lightfoot, David. 1991. How to set paremeters: Arguments from language change. Cambridge, MA: MIT Press.

Lightfoot, David. 1997. Shifting triggers and diachronic reanalyses. In Ans van Kemenade, \& Nigel Vincent (eds.), Parameters of morphosyntactic change, 253-272. Cambridge: Cambridge University Press.

Lightfoot, David. 2006. How new languages emerge. Cambridge: Cambridge University Press.

Mitchell, Bruce. 1968. A guide to Old English. Oxford: Basil Blackwell.

Moore, Samuel \& Thomas A. Knott. 1971. The elements of Old English. Ann Arbor, Michigan: The George Wahr Publishing Co.

Panagiotidis, Phoevos. 2014. Categorial features: A generative theory of word class categories. Cambridge: Cambridge University Press.

Pesetsky, David \& Esther Torrego. 2204/2007. The syntax of valuation and the interpretability of features. In Simin Karimi, Vida Samiian \& Wendy K. Wilkins (eds.), Phrasal and clausal architecture: Syntactic derivation and interpretation. In honor of Joseph E. Emonds, 262-294. Amsterdam \& Philadelphia: John Benjamins Publishing Company.

Pintzuk, Susan. 1991. Phrase structures in competition: Variation and change in Old English word order. Dissertation: University of Pennsylvania.

Pintzuk, Susan. 1993. Verb seconding in Old English: Verb movement to Infl. The Linguistic Review 10. 5-35.

Pintzuk, Susan. 1999. Phrase structures in competition: Variation and change in Old English word order. New York: Garland.

Platzack, Christer. 1988. The emergence of a word order difference in Scandinavian subordinate clauses. McGill Working Papers in Linguistics, Special Issue on Comparative Germanic Syntax, 215-238.

Platzack, Christer \& Anders Holmberg. 1989. The role of AGR and finiteness. Working Papers in Scandinavian Syntax 43: 51-76.

Pollock, Jean-Ives. 1989. Verb movement, Universal Grammar, and the structure of IP. Linguistic Inquiry 20: 365-424.

RAE $=$ Real Academia Española. 2009. Nueva gramática de la lengua española. MorfologíaSintaxis, vol.1. Madrid: Espasa Libros.

Roberts, Ian. 1985. Agreement parameters and the development of English modal auxiliaries. Natural Language and Linguistic Theory 3: 21-58.

Roberts, Ian. 1993. Verbs and diachronic syntax. Dordrecht: Kluwer.

Roberts, Ian. 2007. Diachronic syntax. Oxford: Oxford University Press.

Roberts, Ian. 2011. Head movement and the Minimalist Program. In Cedric Boecx (ed.), The 
Oxford handbook of linguistic Minimalism 195-219. Oxford: Oxford University Press.

Rohrbacher, Bernhard W. 1994. The Germanic languages and the full paradigm: A theory of $V$ to I raising. Amherst, MA: University of Massachusetts dissertation.

Rohrbacher, Bernhard W. 1999. Morphology-driven syntax: A theory of V to I raising and prodrop. Amsterdam \& Philadelphia: John Benjamins Publishing Company.

Ross, John. 1969. Auxiliaries as main verbs. Studies in Philosophical Linguistics 1: 77-102.

Taylor, Ann \& Susan Pintzuk. 2012. Verb order, object position and information statu in Old English. York Papers in Linguistics Series 2: 29-51.

Thráinsson, Hoskuldur. 2010. Predictable and unpredictable sources of variable verb and adverb placement in Scandinavian. Lingua 120: 1062-1088.

Traugott, Elizabeth Closs. 1992. Syntax. In Richard Hogg (ed.), The Cambridge history of the English language, vol. 1, 168-289. Cambridge: Cambridge University Press.

Vikner, Sten. 1995. Verb movement and expletive subjects in the Germanic languages. Oxford: Oxford University Press.

Vikner, Sten. 1997. V-to-I movement and inflection for person in all tenses. In Liliane Haegeman (ed.), The new comparative syntax, 189-213. London: Longman.

Vikner, Sten. 2001. Verb movement variation in Germanic and Optimality Theory. Ms., University of Tübingen.

Vikner, Sten. 2005. Immobile complex verbs in Germanic. Journal of Comparative Germanic Linguistics 8: 83-115.

Warner, Anthony. 1993. English auxiliaries: Structure and history. Cambridge: Cambridge University Press.

Warner, Anthony. 1997. The structure of parametric change and V movement in the history of English. In Ans van Kemenade \& Nigel Vincent (eds.), Parameters of morphosyntactic change, 380-393. Cambridge: Cambridge University Press.

Wiklund, Anna-Lena, Gunnar H. Hrafnbjargarson, Kristine Bentzen \& Porbjörg Hroarsdottir. 2007. Rethinking Scandinavian verb movement. Journal of Comparative Germanic Linguistics 10: 203-233.

Wood, Jim. 2015. Icelandic morphosyntax and argument structure. Heidelberg, Switzerland: Springer Publishing Company.

Wright, Joseph. 1906. An Old High German primer. Oxford: Clarendon Press.

Wright, Joseph \& Elizabeth M. Wright. 1925. Old English grammar. Third edition. Oxford: Oxford University Press. 